\title{
Comparison of Fission Product Release Predictions Using PARFUME with Results from the AGR-1 Safety Tests
}

Blaise P. Collin

The INL is a

U.S. Department of Energy

National Laboratory

operated by

Battelle Energy Alliance

September 2014
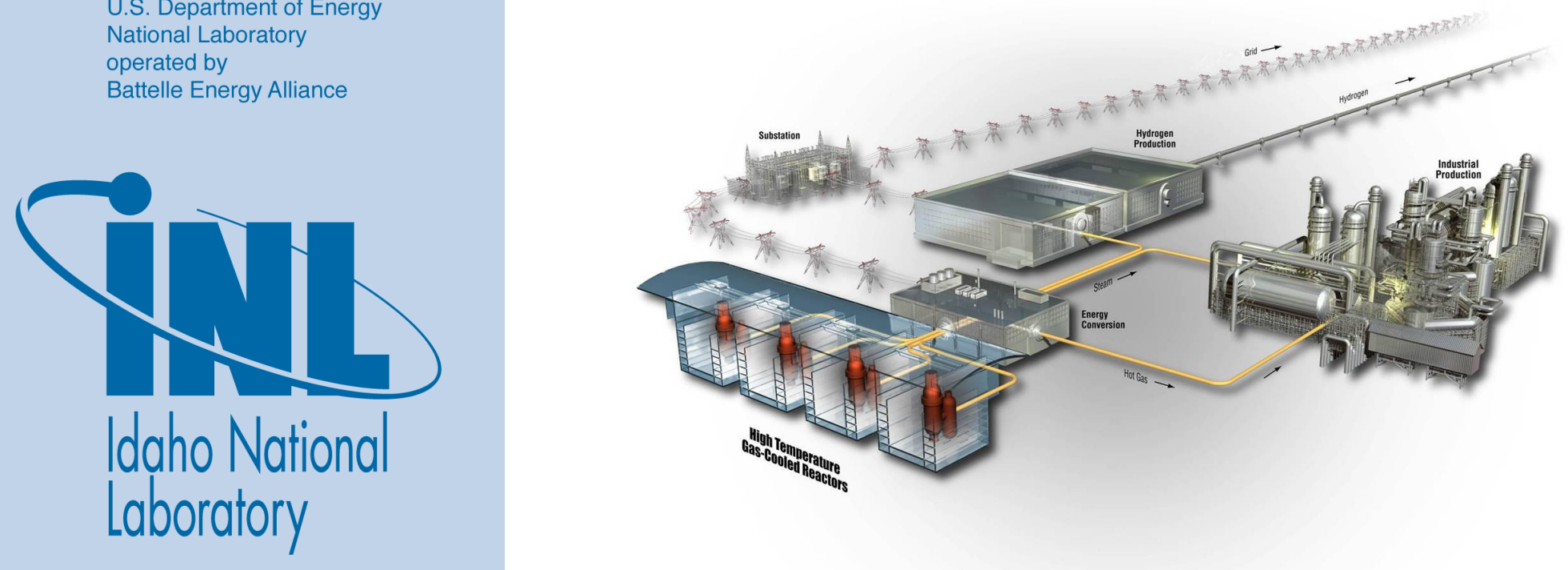


\section{DISCLAIMER}

This information was prepared as an account of work sponsored by an agency of the U.S. Government. Neither the U.S. Government nor any agency thereof, nor any of their employees, makes any warranty, expressed or implied, or assumes any legal liability or responsibility for the accuracy, completeness, or usefulness, of any information, apparatus, product, or process disclosed, or represents that its use would not infringe privately owned rights. References herein to any specific commercial product, process, or service by trade name, trade mark, manufacturer, or otherwise, does not necessarily constitute or imply its endorsement, recommendation, or favoring by the U.S. Government or any agency thereof. The views and opinions of authors expressed herein do not necessarily state or reflect those of the U.S. Government or any agency thereof. 


\title{
Comparison of Fission Product Release Predictions using PARFUME with Results from the AGR-1 Safety Tests
}

\author{
Blaise P. Collin
}

September 2014

\begin{abstract}
Idaho National Laboratory
VHTR Program

Idaho Falls, Idaho 83415
\end{abstract}

http://www.inl.gov

Prepared for the

U.S. Department of Energy

Office of Nuclear Energy

Under DOE Idaho Operations Office

Contract DE-AC07-05ID14517 


\section{VHTR Program}

\section{Comparison of Fission Product Release Predictions using PARFUME with Results from the AGR-1 Safety Tests}

INL/EXT-14-31976

September 2014

Prepared by:

Shais Cllin
Blaise P. Collin
Reviewed by:

Paul A. Demkowicz

Technical Lead, Post Irradiation Examination
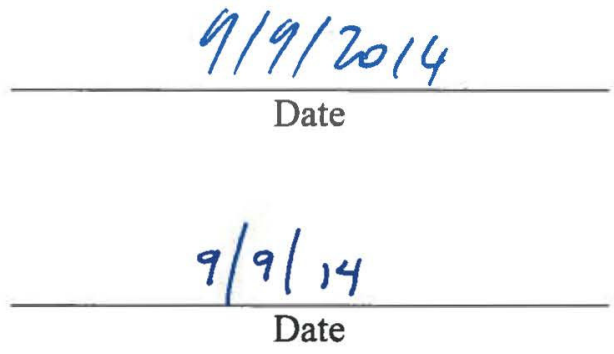

Approved by:

John T. Maki
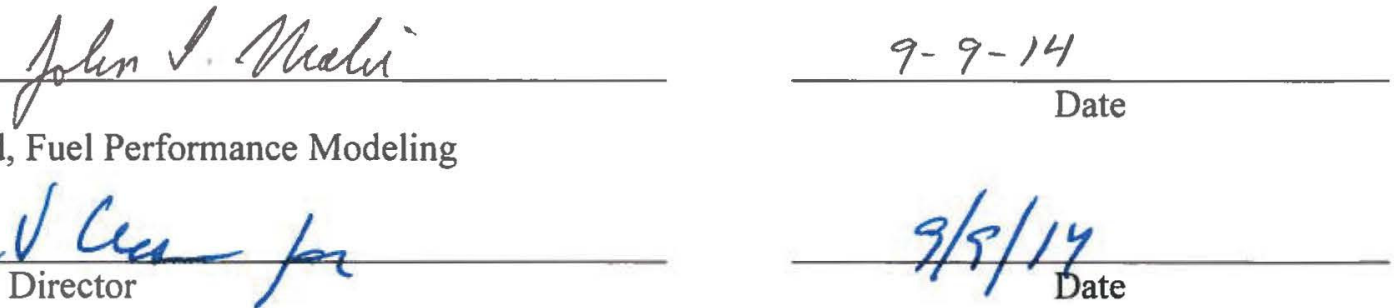

David A. Petti, Director

Very High Temperature Reactor Program

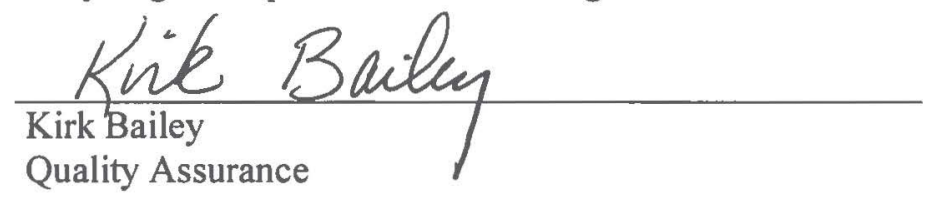

$\frac{9-9.2014}{\text { Date }}$ 


\section{ABSTRACT}

Safety tests were conducted on 14 fuel compacts from AGR-1, the first irradiation experiment of the Advanced Gas Reactor (AGR) Fuel Development and Qualification program, at temperatures ranging from 1600 to $1800^{\circ} \mathrm{C}$ to determine fission product release at temperatures that bound reactor accident conditions. The PARFUME (PARticle FUel ModEl) code was used to predict the release of fission products silver, cesium, strontium, and krypton from fuel compacts containing tristructural isotropic (TRISO) coated particles during the safety tests, and the predicted values were compared with experimental results.

Preliminary comparisons between PARFUME predictions and post-irradiation examination (PIE) results of the safety tests show different trends in the prediction of the fractional release depending on the species, which leads to different conclusions regarding the diffusivities used in the modeling of fission product transport in TRISO-coated particles:

- For silver, the diffusivity in silicon carbide $(\mathrm{SiC})$ might be overestimated by a factor of at least $10^{2}$ to $10^{3}$ at $1600^{\circ} \mathrm{C}$ and $1700^{\circ} \mathrm{C}$, and at least 10 to $10^{2}$ at $1800^{\circ} \mathrm{C}$. The diffusivity of silver in uranium oxy-carbide (UCO) might also be overestimated, but the available data are insufficient to allow definitive conclusions to be drawn.

- For cesium, the diffusivity in UCO might be overestimated by a factor of at least $10^{2}$ to $10^{3}$ at $1600^{\circ} \mathrm{C}, 10^{5}$ at $1700^{\circ} \mathrm{C}$, and $10^{3}$ at $1800^{\circ} \mathrm{C}$. The diffusivity of cesium in $\mathrm{SiC}$ might also be overestimated, by a factor of 10 at $1600^{\circ} \mathrm{C}$ and $10^{3}$ at $1700^{\circ} \mathrm{C}$, based upon the comparisons between calculated and measured release fractions from intact particles. There is no available estimate at $1800^{\circ} \mathrm{C}$ since all the compacts heated up at $1800^{\circ} \mathrm{C}$ contain particles with failed $\mathrm{SiC}$ layers whose release dominates the release from intact particles.

- For strontium, the diffusivity in $\mathrm{SiC}$ might be overestimated by a factor of 10 to $10^{2}$ at 1600 and $1700^{\circ} \mathrm{C}$, and $10^{2}$ to $10^{3}$ at $1800^{\circ} \mathrm{C}$. These values might be somewhat overestimated because the strontium retention during irradiation cannot be assessed a priori, which affects the magnitude of the calculated release during safety testing. The diffusivity of strontium in UCO cannot be derived from these heating tests, but it is assumed to be modeled correctly using the IAEA recommended value for kernel diffusivity.

- For krypton, there is no reliable release data for compacts heated up at $1600^{\circ} \mathrm{C}$, which includes all the compacts containing only intact particles. At 1700 and $1800^{\circ} \mathrm{C}$, comparisons show an overprediction of the release from compacts containing particles with failed SiC by 1 to 1.5 orders of magnitude. There are not sufficient data from these heating tests to determine which of the TRISO-coating's layers diffusivities are under or overestimated.

These overestimation factors were derived by correcting the diffusivities used in PARFUME to obtain a better match between the modeling predictions and the safety testing results. They are summarized in the table below.

\begin{tabular}{|l|c|c|c|c|c|c|}
\hline \multirow{2}{*}{} & \multicolumn{2}{|c|}{ Correction Factor Kernel } & \multicolumn{3}{c|}{ Correction Factor $\mathbf{S i C}$} \\
\cline { 2 - 7 } & $\mathbf{1 6 0 0}^{\circ} \mathbf{C}$ & $\mathbf{1 7 0 0}^{\circ} \mathbf{C}$ & $\mathbf{1 8 0 0}^{\circ} \mathbf{C}$ & $\mathbf{1 6 0 0}^{\circ} \mathbf{C}$ & $\mathbf{1 7 0 0}^{\circ} \mathbf{C}$ & $\mathbf{1 8 0 0}^{\circ} \mathbf{C}$ \\
\hline Silver & - & - & - & $10^{2}-10^{3}$ & $10^{2}-10^{3}$ & $10-10^{2}$ \\
\hline Cesium & $10^{2}-10^{3}$ & $10^{5}$ & $10^{3}$ & 10 & $10^{3}$ & - \\
\hline Strontium & - & - & - & $10-10^{2}$ & $10-10^{2}$ & $10^{2}-10^{3}$ \\
\hline Krypton & - & - & - & - & - & - \\
\hline
\end{tabular}


These estimated correction factors to the diffusivities are based on limited statistics and on safety testing data that show differences from one compact to another at a given temperature, which leads to uncertainties in the assessment of these correction factors. This is especially the case for the correction factors at $1700^{\circ} \mathrm{C}$ that are based on the use of one or two data points, which limits the statistical significance of the analysis. The overprediction might be even larger if the measured release does not originate from the particles. At this point, all these correction factors are preliminary, while a more definitive assessment must await additional data from future AGR safety testing campaigns. 


\section{CONTENTS}

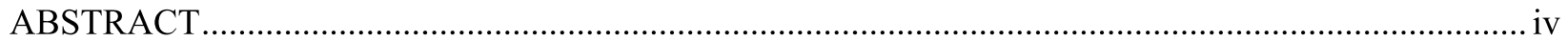

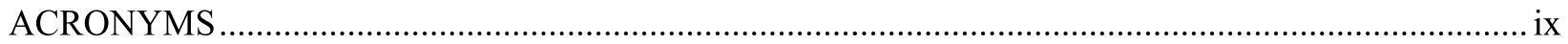

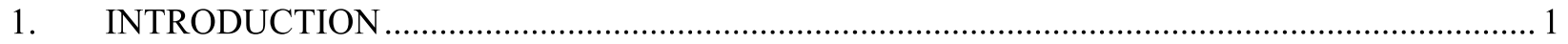

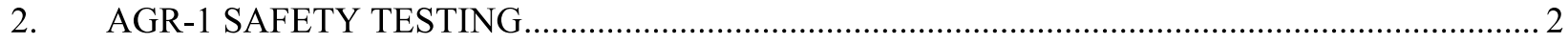

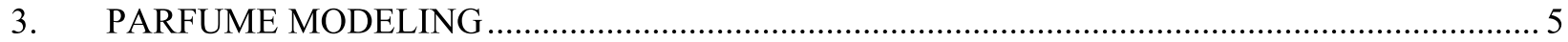

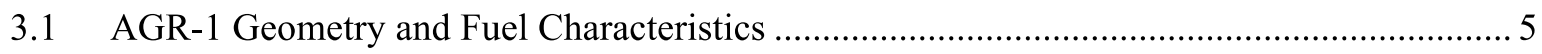

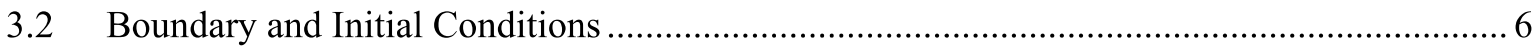

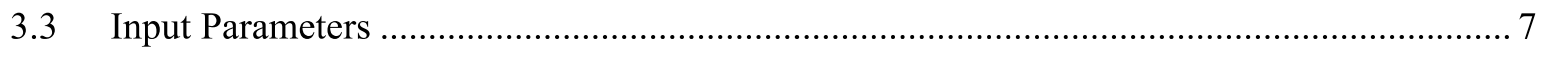

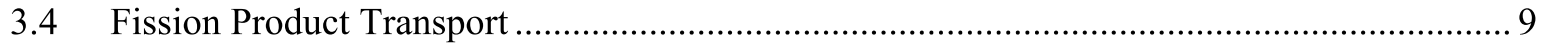

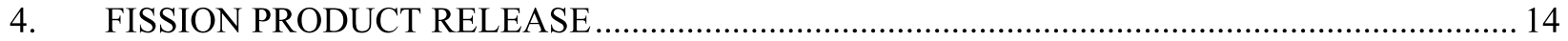

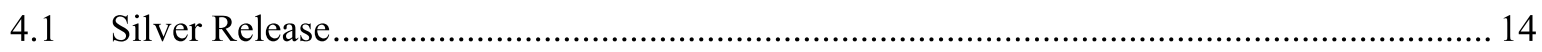

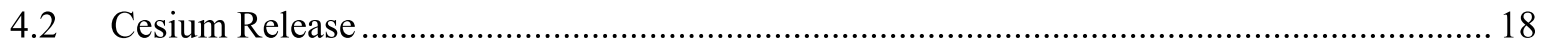

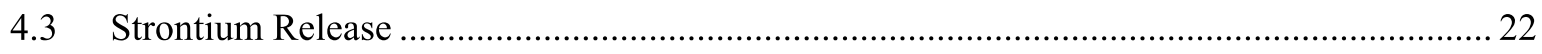

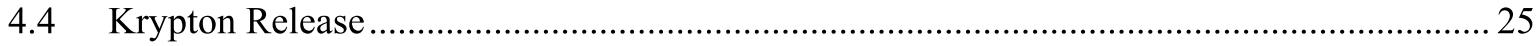

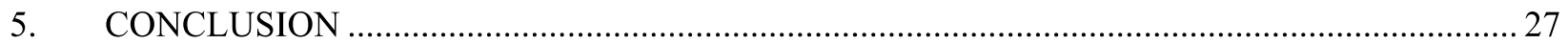

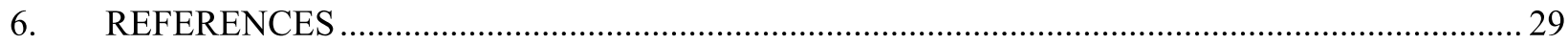




\section{FIGURES}

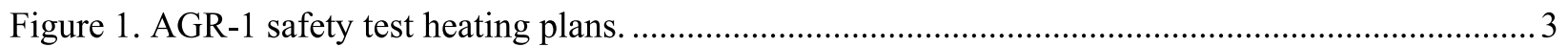

Figure 2. ATR core cross section displaying the B-10 position. ............................................................. 5

Figure 3. Axial schematic of the AGR-1 capsules.................................................................................. 5

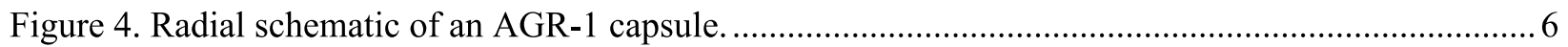

Figure 5. Schematic of a typical TRISO-coated fuel particle. ................................................................ 6

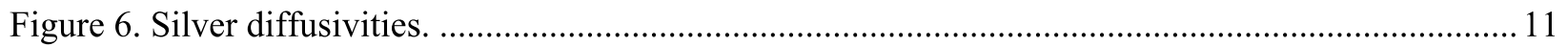

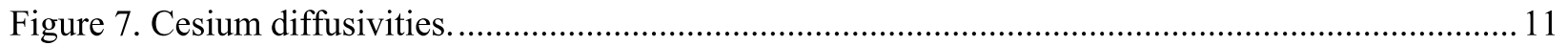

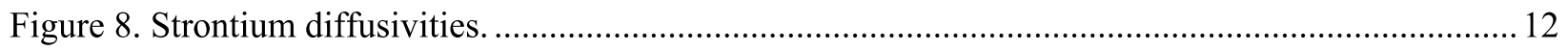

Figure 9. Krypton diffusivities (UO2 Acc denotes the values used during accidental phase)................. 12

Figure 10. Silver fractional release from compacts containing only intact particles.............................. 16

Figure 11. Silver fractional release from compacts containing particles with failed SiC layers. PARFUME predictions include the release from intact particles.

Figure 12. Silver fractional release from compacts containing only intact particles corrected to exclude release during the first $\sim 24$ hours of the safety tests.

Figure 13. Silver fractional release from compacts containing particles with failed SiC layers corrected to exclude release during the first $\sim 24$ hours of the safety tests. PARFUME predictions include the release from intact particles.

Figure 14. Calculated silver release fraction versus diffusivity in SiC during safety testing. ................... 18

Figure 15. Cesium fractional release from compacts containing only intact particles.

Figure 16. Cesium fractional release from compacts containing particles with failed SiC layers. PARFUME predictions exclude the release from intact particles. 20

Figure 17. Calculated cesium release fraction versus diffusivity in the kernel during safety testing.........20

Figure 18. Calculated cesium release fraction versus diffusivity in the kernel during safety testing. The diffusivity of cesium in the kernel during irradiation was reduced by a factor of 100 .

Figure 19. Calculated cesium release fraction versus diffusivity in $\mathrm{SiC}$ during safety testing. The diffusivities of cesium in the kernel and in $\mathrm{SiC}$ during irradiation were reduced by a factor of 100 and by $30 \%$, respectively, and the diffusivity of cesium in the kernel during safety testing was reduced by a factor of 500 at $1600^{\circ} \mathrm{C}$ and 105 at $1700^{\circ} \mathrm{C}$.

Figure 20. Strontium fractional release from compacts containing only intact particles.

Figure 21. Strontium fractional release from compacts containing particles with failed SiC layers. PARFUME predictions include the release from intact particles.

Figure 22. Calculated strontium release fraction versus diffusivity in $\mathrm{SiC}$ during safety testing.

Figure 23. Krypton fractional release from compacts containing particles with failed SiC layers. PARFUME predictions exclude the release from intact particles. 


\section{TABLES}

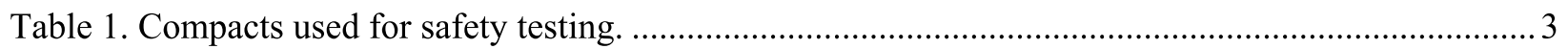

Table 2. Parameters used in the PARFUME modeling of the AGR-1 irradiation.................................... 8

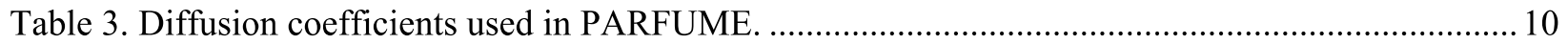

Table 4. Compacts containing particles with failed SiC layers. ............................................................... 14

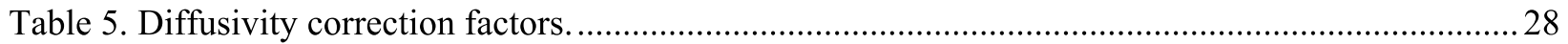




\section{ACRONYMS}

AGR Advanced Gas Reactor

AGR-1 first irradiation test of the AGR program

ASME American Society of Mechanical Engineers

ATR Advanced Test Reactor

BAF Bacon Anisotropy Factor

BISO Bistructural ISOtropic

CCCTF Core Conduction Cooldown Test Facility

CEGA Combustion Engineering / General Atomics

DOE Department of Energy

EFPD Effective Full Power Day

$\mathrm{E}_{\mathrm{n}} \quad$ neutron energy

FACS Fuel Accident Condition Simulator

FGMS Fission Gas Monitoring System

FIMA Fissions per Initial heavy Metal Atom

HTGR High Temperature Gas Reactor

IAEA International Atomic Energy Agency

INL Idaho National Laboratory

IPyC Inner Pyrolytic Carbon

MFC Materials and Fuels Complex

NQA Nuclear Quality Assurance

PARFUME PARticle Fuel ModEl

PIE Post-Irradiation Examination

OPyC Outer Pyrolytic Carbon

ORNL Oak Ridge National Laboratory

$\mathrm{SiC} \quad$ Silicon Carbide

TMAP Tritium Migration Analysis Program

TRISO TRistructural ISOtropic

UCO Uranium oxycarbide

$\mathrm{UO}_{2} \quad$ Uranium dioxide

VHTR Very High Temperature Reactor 


\section{INTRODUCTION}

This report documents comparisons between post-irradiation examination measurements and model predictions of silver $(\mathrm{Ag})$, cesium $(\mathrm{Cs})$, strontium $(\mathrm{Sr})$, and krypton $(\mathrm{Kr})$ release from selected tristructural isotropic (TRISO) fuel compacts that underwent safety testing following the first irradiation test of the Advanced Gas Reactor program (AGR-1). The safety tests discussed in this report were conducted at both Oak Ridge National Laboratory (ORNL) and Idaho National Laboratory (INL) on 14 compacts at isothermal temperatures of 1600,1700 , and $1800^{\circ} \mathrm{C}$.

The heating of AGR-1 compacts is a critical component of the AGR-1 fuel performance evaluation, and its objectives are to identify the effect of fuel type (baseline or variants), safety test temperature, burnup, and irradiation temperature on the performance of the fuel at elevated temperature. The effect of the safety test temperature is especially important as historical data have shown significantly different behavior of the TRISO fuel under accident temperatures of 1600 or $1800^{\circ} \mathrm{C}$. Safety testing of compacts was followed by a detailed examination of the fuel particles to further evaluate fission product retention and behavior of the kernel and coating layers. A primary interest was to identify the source of the release by examining particles with defective coating layers that are more prone to releasing fission products.

The analyses were completed using the particle fuel model computer code PARFUME (PARticle FUel ModEl) developed at INL. PARFUME is an advanced gas-cooled reactor fuel performance modeling and analysis code (Miller 2009). It has been developed as an integrated mechanistic code that evaluates the thermal, mechanical, and physico-chemical behavior of fuel particles during irradiation to determine the failure probability of a population of fuel particles given the particle-to-particle statistical variations in physical dimensions and material properties that arise from the fuel fabrication process, accounting for all viable mechanisms that can lead to particle failure. The code accounts for these calculated particle failures in determining the diffusion of fission products from the fuel through the particle coating layers, and through the fuel matrix to the coolant boundary. The code also determines the diffusion of fission products from the fuel through the particle coating layers, and through the fuel matrix to the coolant boundary. The subsequent release of fission products is calculated at the compact level (release of fission products from the compact). The diffusivity of each layer can be individually set to a high value (typically $10^{-6} \mathrm{~m}^{2} / \mathrm{s}$ ) to simulate a failed layer with no capability of fission product retention. In this study, the comparison to safety test results focused on the release of four fission products: silver, cesium, strontium, and krypton.

PARFUME calculates the release fraction from a compact as the ratio of the number of atoms released from the compact to the amount produced in the compact fuel kernels and through uranium contamination. The release fraction obtained from safety tests was calculated by measuring the amount of fission products released from the compact and by normalizing that amount to a predicted compact inventory obtained by as-run neutronics calculations of the AGR-1 experiment (Sterbentz 2013).

Section 2 gives a brief summary of the safety test results used for comparison to model predictions. Section 3 offers an overview of the modeling with PARFUME. Section 4 presents the results of the testing in terms of fission product release. Conclusions are drawn in Section 5 and references are listed in Section 6.

Calculations were performed with PARFUME Version 2.21.1.1 (as configured by the Revision Control System) compiled with Intel FORTRAN Compiler 11.1.073 on an SGI Altix ICE 8200 platform operating under SUSE Linux Enterprise Server 10. In addition, this study was conducted in accordance to quality standard NQA-1-2008; 1-a-2009, "Quality Assurance Requirements for Nuclear Facility Applications," published by the American Society of Mechanical Engineers (ASME 2009). 


\section{AGR-1 SAFETY TESTING}

The Department of Energy (DOE) Advanced Gas Reactor Fuel Development and Qualification Program was established to qualify TRISO-coated particle fuel for use in High Temperature Gas Reactors (HTGRs). The primary goal of the program is to provide a baseline fuel qualification data set in support of the licensing and operation of an HTGR (Simonds 2014).

Several fuel and material irradiation experiments are planned for the DOE AGR program. The goals of these experiments are to provide irradiation performance data to support fuel process development, qualify fuel for normal operating conditions, support development and validation of fuel performance and fission product transport models and codes, and provide irradiated fuel and materials for post-irradiation examination and safety testing (Simonds 2014).

AGR-1 is the first of these irradiation tests. Irradiation began in the Advanced Test Reactor (ATR) at INL in December of 2006 and ended in November 2009. AGR-1 was intended to serve as a shakedown test of a multi-capsule design to be used in subsequent irradiations, and to test early variants of the fuel produced under the DOE AGR program (Maki 2009). A total of 72 compacts were irradiated in the AGR1 experiment in six different capsules. The experiment completed 620 effective full power days (EFPD) in the reactor and achieved calculated peak burnup of $19.6 \%$ fissions per initial heavy metal atom (FIMA) and fast neutron fluence of $4.30 \times 10^{25} \mathrm{n} / \mathrm{m}^{2}, \mathrm{E}_{\mathrm{n}}>0.18 \mathrm{MeV}$ (Collin 2014a).

At completion of the irradiation, the AGR-1 test train was shipped to the Materials and Fuels Complex (MFC) at INL for PIE. Safety testing of selected irradiated compacts was conducted at the ORNL Core Conduction Cooldown Test Facility (CCCTF) and at the INL Fuel Accident Condition Simulator (FACS). The objectives of the AGR-1 PIE and associated safety testing are to assess the overall performance of the test train and components and provide data to verify the test train thermal analyses, verify the particle coating integrity and evaluate the fission product retention of the fuel during normal irradiation and during high-temperature post-irradiation safety tests, and characterize the fuel compacts and individual particles to assess the condition of the matrix material, kernels, and coatings (Demkowicz 2010).

The objectives of the safety testing campaign were to identify the effects of fuel type (baseline or variants), accident test temperature, burnup, and irradiation temperature on the performance of the fuel at elevated temperatures. Safety tests involved heating compacts for at least 300 hours to maximum temperatures of 1600 to $1800^{\circ} \mathrm{C}$, where $1600^{\circ} \mathrm{C}$ is the expected maximum temperature during a hightemperature gas-cooled reactor depressurization conduction cooldown event, and $1800^{\circ} \mathrm{C}$ is the expected temperature at which the performance of the $\mathrm{SiC}$ layer will begin to degrade. The times used in these tests are much greater than calculated to occur in an actual modular HTGR, but they are typical of historic testing conducted during German TRISO fuel development.

Because of programmatic funding and time constraints, only about one-fourth of the AGR-1 compacts underwent safety tests. Specific irradiated compacts were selected for examination based on a detailed set of criteria, including the need to examine the different fuel types and to span a range of irradiation temperature and burnup (Demkowicz 2012a). Table 1 lists the 14 compacts discussed in this report, while Figure 1 shows the safety test heating schedule used in the experiments (Baldwin 2014). 
Table 1. Compacts used for safety testing.

\begin{tabular}{|c|c|c|c|c|c|c|c|}
\hline Compact $^{(\mathbf{a})}$ & $\begin{array}{c}\text { Burnup } \\
\text { (\%FIMA) }\end{array}$ & $\begin{array}{c}\text { Fast } \\
\text { Fluence } \\
\left(\times 10^{25} \mathrm{n} / \mathrm{m}^{2}\right. \\
\mathrm{E}_{\mathbf{n}}>\mathbf{0 . 1 8} \\
\mathrm{MeV})\end{array}$ & $\begin{array}{c}\text { Safety Test } \\
\text { Temperature } \\
\left({ }^{\circ} \mathrm{C}\right)\end{array}$ & Compact & $\begin{array}{c}\text { Burnup } \\
\text { (\%FIMA) }\end{array}$ & $\begin{array}{c}\text { Fast } \\
\text { Fluence } \\
\left(\times 10^{25} \mathrm{n} / \mathrm{m}^{2}\right. \\
\mathrm{E}_{\mathrm{n}}>\mathbf{0 . 1 8} \\
\mathrm{MeV})\end{array}$ & $\begin{array}{c}\text { Safety Test } \\
\text { Temperature } \\
\left({ }^{\circ} \mathrm{C}\right)\end{array}$ \\
\hline $6-4-3$ & 13.35 & 2.46 & 1600 & $4-3-3$ & 18.63 & 4.16 & 1600 \\
\hline $6-4-1$ & 13.35 & 2.43 & 1600 & 4-3-2 & 16.38 & 3.68 & 1800 \\
\hline $6-2-1$ & 14.20 & 2.87 & 1600 & $4-1-2$ & 17.39 & 3.72 & 1600 \\
\hline $5-3-3$ & 17.01 & 3.65 & 1600 & 3-3-2 & 17.02 & 3.8 & 1600 \\
\hline $5-1-3$ & 18.19 & 3.82 & 1800 & $3-3-1$ & 19.07 & 4.23 & 1700 \\
\hline $4-4-3$ & 18.99 & 4.06 & 1700 & $3-2-3$ & 19.12 & 4.28 & 1800 \\
\hline $4-4-1$ & 18.96 & 3.99 & 1800 & $3-2-2$ & 17.02 & 3.79 & 1600 \\
\hline
\end{tabular}

a. Compacts heated-up at $1600^{\circ} \mathrm{C}$ are highlighted in blue, at $1700^{\circ} \mathrm{C}$ in green, and at $1800^{\circ} \mathrm{C}$ in red.

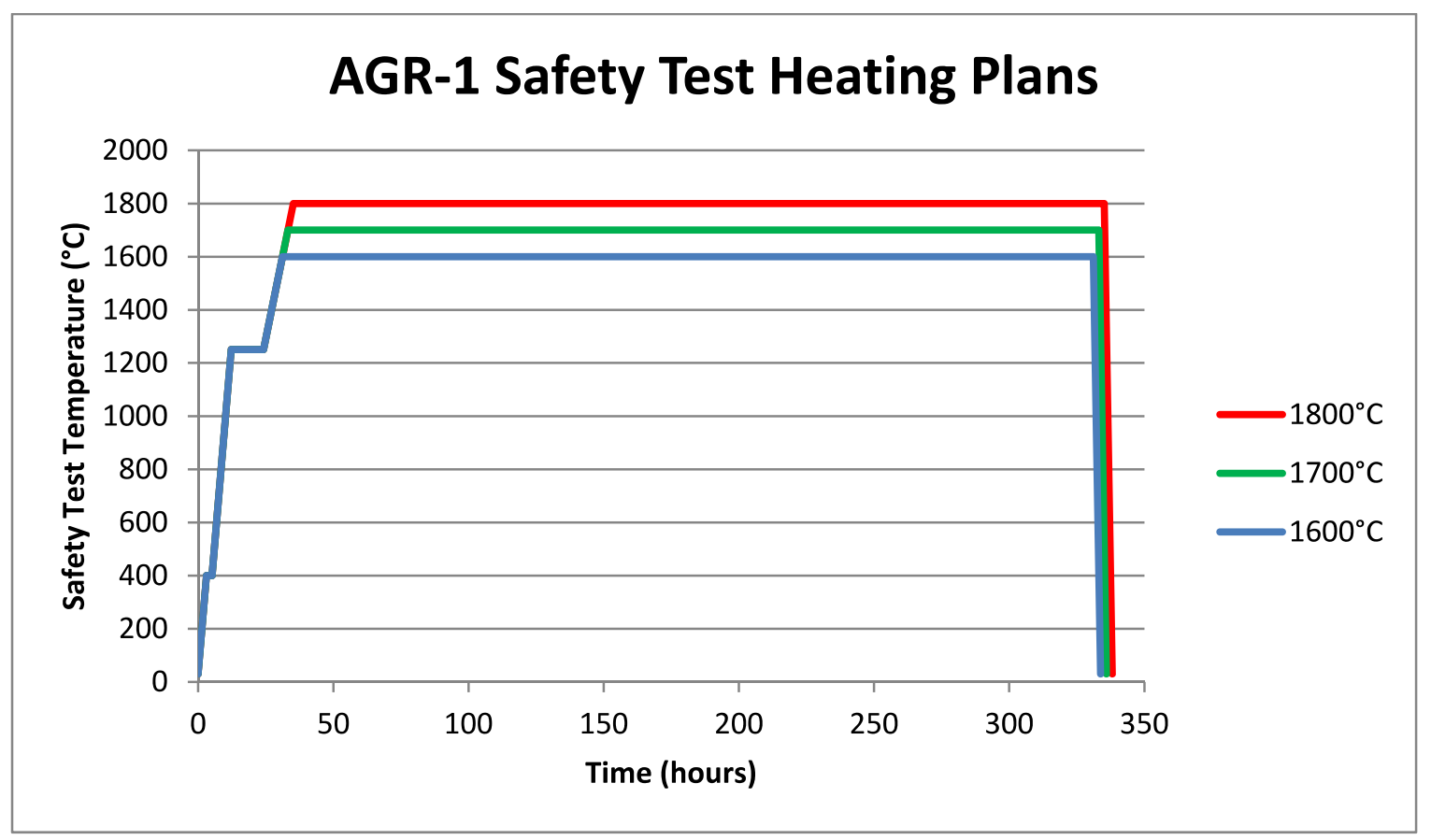

Figure 1. AGR-1 safety test heating plans.

Safety tests were conducted in two different facilities: ORNL and INL. At ORNL, during the test period, condensable fission products (including $\mathrm{Ag}, \mathrm{Cs}$, and $\mathrm{Sr}$ ) were collected by the CCCTF in-furnace cold finger and gaseous fission products (including $\mathrm{Kr}$ ) were collected from the helium sweep gas as it passed through liquid nitrogen-cooled cold traps. Deposition cups attached to the in-furnace cold finger were periodically removed and analyzed by gamma spectrometry and the sweep gas traps were constantly monitored for gamma activity throughout each run. After completion of each safety test, acid leaching and additional analysis were performed on the deposition cups and CCCTF furnace internals (graphite fuel holder, tantalum furnace liner, and tantalum gas inlet line) to account for the entire inventory of fission products released from the compact. An average deposition cup collection efficiency for each detectable fission product was calculated by determining the fraction of each fission product deposited on all the cups combined versus the total fission product release at the end of the test. This average collection 
efficiency was then applied to the time-dependent deposition cup data to estimate the total time-dependent fission product release from the compact (Baldwin 2014).

At INL, the fuel compacts were heated in the FACS furnace located at MFC. In the FACS furnace, fuel specimens are supported on a tantalum holder inside a tantalum flow tube. High-purity helium is injected into the flow tube, sweeps past the fuel specimen and out the top of the flow tube, and then flows out of the furnace to the Fission Gas Monitoring System (FGMS). A water-cooled cold finger is used to position a steel condensation plate immediately above the hot zone and in the path of helium flow as it exits the flow tube. Condensation plates are used to collect condensable fission products during a test, and can be exchanged during furnace operation so that time-dependent data on fission product release from the fuel can be obtained. The FGMS consists of two lead-shielded, cryogenically-cooled charcoal traps used to retain fission gases that are released from the fuel during a test and carried to the traps along with the helium sweep gas. Each cold trap is continuously monitored with a high-purity germanium gamma detector during a test to provide real-time data on the buildup of radioactive fission gases (Demkowicz 2012b). 


\section{PARFUME MODELING}

\subsection{AGR-1 Geometry and Fuel Characteristics}

AGR-1 test train was irradiated in the $38.1-\mathrm{mm}$ (1.5-inch) diameter B-10 position of the ATR at INL. An ATR core cross section indicating this location is displayed in Figure 2. The test train contains six capsules arranged vertically as shown in Figure 3. Each AGR-1 capsule is $152.4 \mathrm{~mm}$ (6 inch) long and contains 12 fuel compacts arranged in three vertical stacks with each stack containing four compacts. Figure 4 illustrates a radial view of a capsule.

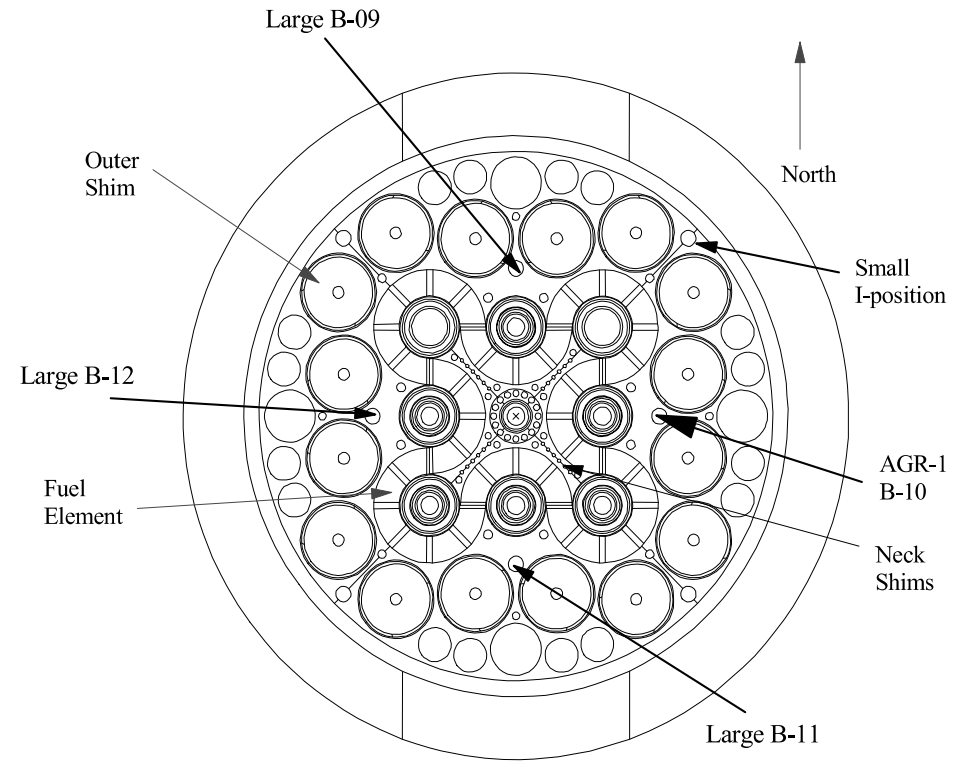

Figure 2. ATR core cross section displaying the B-10 position.

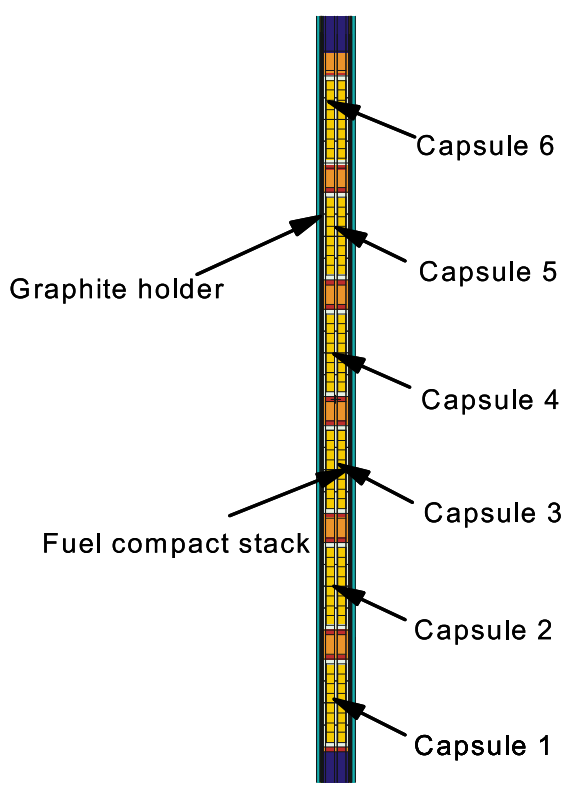

Figure 3. Axial schematic of the AGR-1 capsules. 


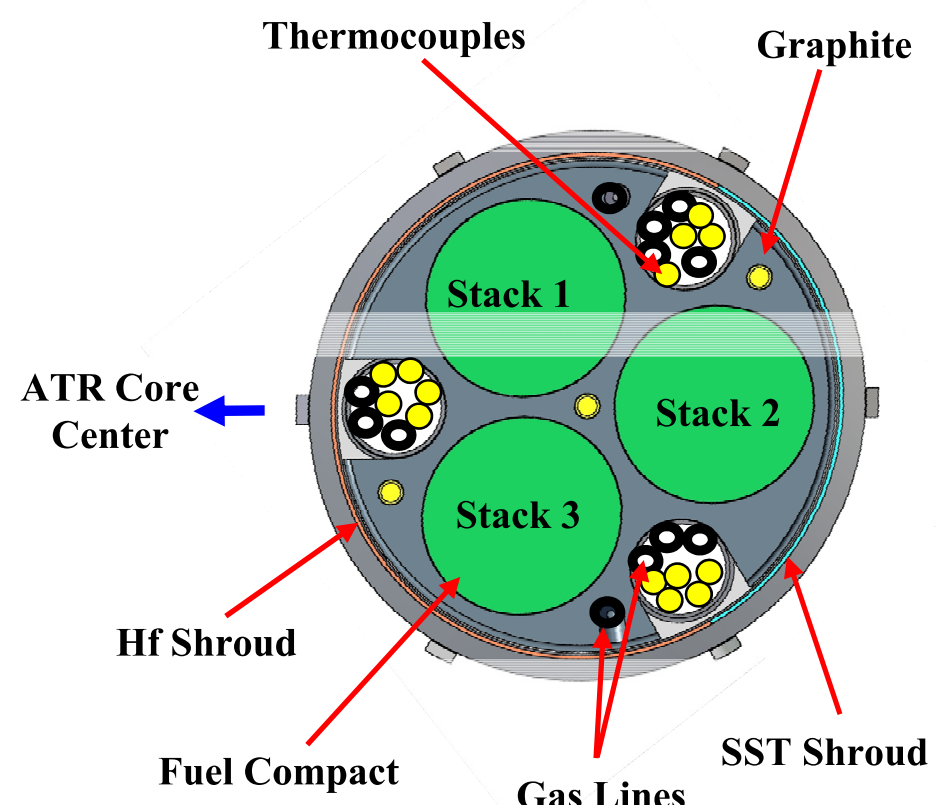

Figure 4. Radial schematic of an AGR-1 capsule.

AGR-1 compacts are right cylinders nominally $25.1 \mathrm{~mm}$ in length and $12.4 \mathrm{~mm}$ in diameter. Each compact contains $\sim 4,100$ fuel particles uniformly dispersed in a matrix composed of a thermosetting carbonaceous material. Each particle has a nominal diameter of $\sim 800 \mu \mathrm{m}$ and contains a kernel consisting of uranium oxycarbide (UCO) fuel. The kernel is coated with a porous buffer layer to accommodate fission product accumulation, a $\mathrm{SiC}$ layer to retain the fission products, and inner and outer pyrocarbon (IPyC and OPyC) layers to protect the silicon carbide as depicted in Figure 5. AGR-1 irradiation in ATR reached 620.2 effective full power days (Collin 2014a). Key aspects of the AGR-1 characteristics needed for PARFUME modeling are described below.

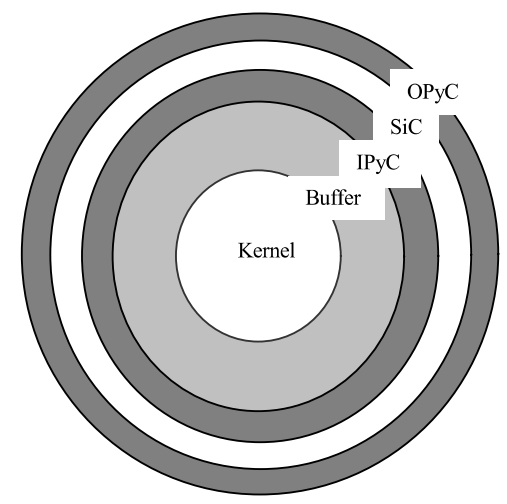

Figure 5. Schematic of a typical TRISO-coated fuel particle.

\subsection{Boundary and Initial Conditions}

PARFUME is designed to evaluate fuel performance based on user inputs for fast neutron fluence and burnup with a corresponding set of thermal conditions. The neutronics and thermal conditions for all the compacts used for comparison to PIE measurements are based on results obtained from as-run neutronics 
calculations and as-run thermal analysis (Sterbentz 2013, Hawkes 2012). The calculations were computed prior to completion of PIE, and they are based on an earlier version of the as-run neutronics calculations (Sterbentz 2011). The difference between the two sets of calculations is on burnup values, and it does not exceed $1.2 \%$. Therefore, there is no impact on the calculated results of the irradiation phase.

PARFUME assumes that all particles in a compact experience similar irradiation and thermal histories over the course of irradiation. Practically, PARFUME models one particle using the average burnup and fast neutron fluence and the volume-averaged temperature of the whole compact. In this scheme, PARFUME statistically treats a collection of particles within a range of geometrical dimensions (see Table 2 in Section 3.3), but all the particles experience the same irradiation and thermal histories.

The 620 days of irradiation are modeled for each compact with the end-of-irradiation values of burnup and fast neutron fluence displayed in Table (see Section 2). Burnup and fast neutron fluence are assumed to evolve linearly during irradiation. The assumption is validated by the linear increase of the compact burnup and fast neutron fluence values reached at the end of each AGR-1 cycle, as reported in the AGR-1 as-run report (Collin 2014a).

The thermal history evolves on a daily basis. For each compact, the daily temperatures of all the calculation nodes are averaged, and PARFUME uses the resulting volume-averaged compact daily temperatures to set the thermal history of the modeled TRISO particle. The daily temperatures are set as boundary conditions at the outer edge of the OPyC. From the OPyC boundary temperature, PARFUME calculates the temperature profile between the $\mathrm{OPyC}$ and the kernel center, taking into account that the temperature profile is affected throughout irradiation by the width of the gap forming between the buffer and the IPyC layer.

Following the modeling of the irradiation phase, PARFUME models the heating phase using the designed heating plans (see Figure 1 in Section 2). The heating plans for isothermally tested compacts consists of two temperature ramps of $120^{\circ} \mathrm{C} / \mathrm{hr}$ followed by temperature plateaus of 2 hours and 12 hours respectively, and then a temperature ramp of $50^{\circ} \mathrm{C} / \mathrm{hr}$ until the maximum temperature $(1600,1700$, or $1800^{\circ} \mathrm{C}$ ) is reached. A heating phase of at least 300 hours follows at maximum temperature and then the compacts are brought back to room temperature $\left(30^{\circ} \mathrm{C}\right)$ with a ramp of $-600^{\circ} \mathrm{C} / \mathrm{hr}$ (Baldwin 2014). During safety tests, the burnup and fast neutron fluence do not evolve and they keep their end-of-irradiation values.

The objective of the PARFUME calculations is to provide the estimated fractional release of fission product species $\mathrm{Ag}, \mathrm{Cs}, \mathrm{Sr}$, and $\mathrm{Kr}$ during the heating phase. The corresponding release fraction is defined as the amount of fission products released during the heating phase relative to the total inventory produced during irradiation. Consequently, the release fraction during the heating phase is equal to the total release fraction (total amount released during irradiation and heating phases divided by total inventory) minus the release fraction of the irradiation phase (amount released during irradiation divided by total inventory).

\subsection{Input Parameters}

The input parameters needed to model the AGR-1 irradiation with PARFUME are listed in Table 2. They originate from:

- The AGR-1 Irradiation Experiment Test Plan (Maki 2009) for the fuel characteristics, particle geometry, compact characteristics, and material non-mechanical properties.

- A CEGA Corporation report (CEGA 1993) for the material mechanical properties. 
Table 2. Parameters used in the PARFUME modeling of the AGR-1 irradiation.

\begin{tabular}{|c|c|c|c|c|}
\hline \multirow[t]{2}{*}{ Category } & \multirow[t]{2}{*}{ Parameter } & \multicolumn{3}{|c|}{$\begin{array}{c}\text { Fuel type }^{(\mathrm{a})} \\
\text { Mean Value } \pm \text { Standard Deviation }\end{array}$} \\
\hline & & Baseline & Variant 1 & Variant 3 \\
\hline \multirow{4}{*}{ Fuel characteristics } & $\mathrm{U}^{235}$ enrichment $(\mathrm{wt} \%)^{(\mathrm{b})}$ & \multicolumn{3}{|c|}{19.736} \\
\hline & Oxygen/uranium (atomic ratio) ${ }^{(\mathrm{b})}$ & \multicolumn{3}{|c|}{1.3613} \\
\hline & Carbon/uranium (atomic ratio) ${ }^{(\mathrm{b})}$ & \multicolumn{3}{|c|}{0.3253} \\
\hline & Uranium contamination fraction ${ }^{(b)}$ & $3.64 \times 10^{-7}$ & $2.75 \times 10^{-7}$ & $1.26 \times 10^{-7}$ \\
\hline \multirow{6}{*}{ Particle geometry } & Kernel diameter $(\mu \mathrm{m})$ & \multicolumn{3}{|c|}{$349.7 \pm 9.0$} \\
\hline & Buffer thickness $(\mu \mathrm{m})$ & $103.5 \pm 8.2$ & $102.5 \pm 7.1$ & $104.2 \pm 7.8$ \\
\hline & IPyC thickness $(\mu \mathrm{m})$ & $39.4 \pm 2.3$ & $40.5 \pm 2.4$ & $38.8 \pm 2.1$ \\
\hline & SiC thickness $(\mu \mathrm{m})$ & $35.3 \pm 1.3$ & $35.7 \pm 1.2$ & $35.9 \pm 2.1$ \\
\hline & OPyC thickness $(\mu \mathrm{m})$ & $41.0 \pm 2.1$ & $41.1 \pm 2.4$ & $39.3 \pm 2.1$ \\
\hline & Particle asphericity ( $\mathrm{SiC}$ aspect ratio) & \multicolumn{3}{|c|}{1.040} \\
\hline \multirow{3}{*}{$\begin{array}{l}\text { Compact } \\
\text { characteristics }\end{array}$} & Diameter (mm) & 12.36 & 12.36 & 12.34 \\
\hline & Number of particles per compact & 4154 & 4145 & 4132 \\
\hline & Compact matrix density $\left(\mathrm{g} / \mathrm{cm}^{3}\right)$ & 1.297 & 1.256 & 1.344 \\
\hline \multirow{12}{*}{ Material properties } & IPyC Weibull modulus $^{(\mathrm{b})}$ & \multicolumn{3}{|c|}{9.5} \\
\hline & SiC Weibull modulus ${ }^{(b)}$ & \multicolumn{3}{|c|}{6.0} \\
\hline & OPyC Weibull modulus ${ }^{(\mathrm{b})}$ & \multicolumn{3}{|c|}{9.5} \\
\hline & IPyC / $\mathrm{SiC}$ bond strength $(\mathrm{MPa})^{(\mathrm{c})}$ & \multicolumn{3}{|c|}{100.0} \\
\hline & PyC Poisson's ratio in creep ${ }^{(b)}$ & \multicolumn{3}{|c|}{0.5} \\
\hline & PyC creep coefficient amplifier & \multicolumn{3}{|c|}{2.0} \\
\hline & Kernel density $\left(\mathrm{g} / \mathrm{cm}^{3}\right)^{(\mathrm{b})}$ & \multicolumn{3}{|c|}{10.924} \\
\hline & Buffer density $\left(\mathrm{g} / \mathrm{cm}^{3}\right)^{(\mathrm{b})}$ & \multicolumn{3}{|c|}{1.10} \\
\hline & IPyC density $\left(\mathrm{g} / \mathrm{cm}^{3}\right)^{(\mathrm{c})}$ & 1.904 & 1.853 & 1.904 \\
\hline & OPyC density $\left(\mathrm{g} / \mathrm{cm}^{3}\right)^{(\mathrm{c})}$ & 1.907 & 1.898 & 1.911 \\
\hline & IPyC (post compact anneal) $\mathrm{BAF}^{(\mathrm{c})}$ & 1.022 & 1.014 & 1.029 \\
\hline & OPyC (post compact anneal) $\mathrm{BAF}^{(\mathrm{c})}$ & 1.019 & 1.013 & 1.021 \\
\hline Boundary conditions & Ambient pressure $(\mathrm{MPa})$ & \multicolumn{3}{|c|}{0.1} \\
\hline
\end{tabular}

a. Baseline fuel in Capsules 3 and 6, Variant 1 in Capsule 5, and Variant 3 in Capsule 4.

b. Standard deviation not considered in PARFUME.

c. Standard deviation not included in these AGR-1 calculations.

In addition, as-run neutronics calculations and as-run thermal analysis are used for the boundary conditions (see Section 3.2), and diffusion coefficients used for fission product transport are derived from the International Atomic Energy Agency (IAEA) Technical Document 978 (IAEA 1997) (see Section 3.4).

As indicated in Table 2, a baseline fuel type and two fuel variant types are tested. Baseline fuel is used in Capsules 3 and 6, Variant 1 fuel is used in Capsule 5, and Variant 3 fuel is used in Capsules 1 and 4. Statistical variations are considered relative to the fuel particle geometry only (kernel diameter, buffer, pyrolytic carbon (PyC), and $\mathrm{SiC}$ thicknesses). PARFUME also has the capability to address statistical variations in creep, bond strength, PyC densities, and PyC Bacon Anisotropy Factors (BAF). With the exception of creep and bond strength, the AGR-1 Irradiation Experiment Test Plan (Maki 2009) provides information regarding these variations. However, results from sensitivity calculations indicated that these 
variations have little impact on the probability of AGR-1 fuel particle failure (Miller 2007). Because the effects are so small, statistical variations in PyC densities and BAF are not considered in these AGR-1 calculations.

The asphericity mentioned in Table 2 is considered at the SiC layer, as required by PARFUME inputs. Asphericity measurements reported in the AGR-1 Irradiation Experiment Test Plan correspond to asphericity at the OPyC layer. The asphericity of AGR-1 fuel particles at the SiC layer was not measured during the coating process, but post-coating optical inspection showed that asphericity at that layer is limited. Asphericity at the SiC layer was measured at a mean value of 1.037 for AGR-2 UCO fuel (Collin 2011). Therefore, a value of 1.040 is a conservative upper limit. Furthermore, previous sensitivity studies concluded that variations in asphericity at this level had a negligible impact on the probability of AGR-1 fuel particle failure (Miller 2007).

The material mechanical properties used in PARFUME are obtained from a report compiled by the CEGA Corporation (CEGA 1993). Table 2 displays parameters used in PARFUME user inputs. Material properties directly incorporated into the PARFUME code source are discussed by (Miller 2007 and 2009).

\subsection{Fission Product Transport}

Fission product transport in PARFUME is based on coding extracted from the Tritium Migration Analysis Program Version 4 (TMAP4) computer code. Originally developed to assist in the evaluation of tritium losses from fusion reactor systems, TMAP4 incorporates a one-dimensional diffusion capability that determines the thermal response of structures and solves equations for solute atom movement through surfaces and in bulk materials (Longhurst 1992).

The coding extracted from TMAP4 was modified for use within PARFUME to calculate fission product transport from the kernel through the successive coating layers of a TRISO-coated fuel particle, from individual TRISO-coated fuel particles to the surrounding matrix, and from the surrounding matrix to the outside of the fuel sphere or compact, which constitutes the release of the fission products.

Fission product transport in PARFUME is a three-step process that includes a fuel element thermal analysis, thermal and fission product transport analyses for fuel particles, and a fuel element fission product transport analysis ultimately leading to fission product release. Thermal analyses are performed to acknowledge the temperature dependence of diffusion. Diffusion is first calculated for individual fuel particles. Results from each particle then serve as time- and position-dependent fission product sources for the subsequent fuel element transport analysis.

Fission product transport was calculated for the four following fission products: silver (Ag), cesium (Cs), strontium ( $\mathrm{Sr}$ ), and krypton (Kr). Diffusion coefficients used in PARFUME for each of these species in the successive coating layers and matrix are derived from the IAEA (IAEA 1997) and displayed in Table 3. The corresponding diffusivities can be calculated using these diffusion coefficients in the following Arrhenius-type equation:

where

$$
\mathrm{D}=\mathrm{D}_{0,1} \mathrm{e}^{-\frac{\mathrm{Q}_{0,1}}{\mathrm{RT}}}+\mathrm{D}_{0,2} \mathrm{e}^{-\frac{\mathrm{Q}_{0,2}}{\mathrm{RT}}}
$$

$\mathrm{D}_{0, \mathrm{i}}=$ pre-exponential factor $\left(\mathrm{m}^{2} / \mathrm{s}\right)$

$\mathrm{Q}_{0, \mathrm{i}}=$ activation energy $(\mathrm{kJ} / \mathrm{mol})$

$\mathrm{R}=$ gas constant $\left(8.3142 \times 10^{-3} \mathrm{~kJ} / \mathrm{mol} / \mathrm{K}\right)$

$\mathrm{T}=$ temperature $(\mathrm{K})$

The diffusion coefficients in Table 3 have been derived from the evaluation of numerous irradiation and heating experiments. They are defined as "effective" diffusion coefficients, "effective" meaning that all possible transport mechanisms are summarized in a single transport process. The use of these effective diffusion coefficients is to be considered with care. These coefficients were determined for uranium dioxide (UO2) fuel and associated particle coatings of German fabrication, whose properties may be 
different than these of the UCO fuel of the AGR-1 experiment. Furthermore, in many cases, they are partly based on data from post-irradiation heating tests, which do not take into account the irradiation effects and are conducted at higher temperatures than usual irradiation experiments. Consequently, IAEA diffusivities are not necessarily well adapted to model fission product transport of the AGR-1 irradiation and safety testing experiments.

Table 3. Diffusion coefficients used in PARFUME.

\begin{tabular}{|c|c|c|c|c|c|c|}
\hline Species & $\begin{array}{c}\mathrm{D}_{0, \mathrm{i}}\left(\mathrm{m}^{2} / \mathrm{s}\right) \\
\mathbf{Q}_{0, \mathrm{i}} \\
(\mathrm{kJ} / \mathrm{mol})\end{array}$ & Kernel $^{(\mathbf{a})}$ & Buffer & PyC & $\mathrm{SiC}$ & $\begin{array}{c}\text { Matrix } \\
\text { graphite }\end{array}$ \\
\hline \multirow{3}{*}{ Ag } & $D_{0,1}$ & $6.7 \times 10^{-9}$ & $10^{-8}$ & $5.3 \times 10^{-9}$ & $3.6 \times 10^{-9}$ & 1.6 \\
\hline & $\mathbf{Q}_{0,1}$ & 165 & 0 & 154 & 215 & 258 \\
\hline & $\begin{array}{l}\mathbf{D}_{0,2} \\
\mathbf{Q}_{0,2}\end{array}$ & - & - & - & - & - \\
\hline \multirow{2}{*}{ Cs } & $\begin{array}{l}D_{0,1} \\
Q_{0,1}\end{array}$ & $\begin{array}{c}5.6 \times 10^{-8} \\
209\end{array}$ & $\begin{array}{c}10^{-8} \\
0 \\
\end{array}$ & $\begin{array}{c}6.3 \times 10^{-8} \\
222\end{array}$ & $\begin{array}{c}5.5 \times 10^{-14} \\
125\end{array}$ & $\begin{array}{c}3.6 \times 10^{-4} \\
189\end{array}$ \\
\hline & $\begin{array}{l}D_{0,2} \\
Q_{0,2}\end{array}$ & $\begin{array}{c}5.2 \times 10^{-4} \\
362 \\
\end{array}$ & - & - & $\begin{array}{c}1.6 \times 10^{-2} \\
514 \\
\end{array}$ & - \\
\hline \multirow{2}{*}{$\mathrm{Sr}$} & $\begin{array}{l}D_{0,1} \\
Q_{0,1}\end{array}$ & $\begin{array}{c}2.2 \times 10^{-3} \\
488\end{array}$ & $\begin{array}{r}10^{-8} \\
- \\
\end{array}$ & $\begin{array}{c}2.3 \times 10^{-6} \\
197\end{array}$ & $\begin{array}{c}1.2 \times 10^{-9} \\
205\end{array}$ & $\begin{array}{l}10^{-2} \\
303 \\
\end{array}$ \\
\hline & $\begin{array}{l}D_{0,2} \\
Q_{0,2}\end{array}$ & - & - & - & $\begin{array}{c}1.8 \times 10^{6} \\
791\end{array}$ & - \\
\hline \multirow{2}{*}{$\mathbf{K r}$} & $\begin{array}{l}D_{0,1} \\
Q_{0,1}\end{array}$ & $\begin{array}{c}1.3 \times 10^{-12} / 8.8 \times 10^{-15(b)} \\
126 / 54^{(b)} \\
\end{array}$ & $\begin{array}{c}10^{-8} \\
0 \\
\end{array}$ & $\begin{array}{c}2.9 \times 10^{-8} \\
291 \\
\end{array}$ & $\begin{array}{c}3.7 \times 10^{1} / 8.6 \times 10^{-10(\mathrm{c})} \\
657 / 326^{(\mathrm{c})} \\
\end{array}$ & $\begin{array}{c}6.0 \times 10^{-6} \\
0 \\
\end{array}$ \\
\hline & $\begin{array}{l}D_{0,2} \\
Q_{0,2}\end{array}$ & $\begin{array}{c}0 / 6.0 \times 10^{-1(b)} \\
0 / 480^{(b)} \\
\end{array}$ & - & $\begin{array}{c}2.0 \times 10^{5} \\
923\end{array}$ & 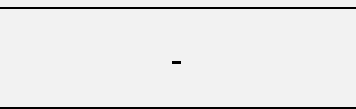 & - \\
\hline
\end{tabular}

a. Kernel diffusivities are obtained from $\mathrm{UO}_{2}$ data.

b. First values are for normal operating conditions, second values are for accident conditions.

c. First values are for $\mathrm{T}>1625.9 \mathrm{~K}$, second values are for $\mathrm{T} \leq 1625.9 \mathrm{~K}$.

Figures 6 through 9 display the diffusivities of silver, cesium, strontium, and krypton as a function of temperature in the successive layers of a particle and compact. From these plots, the following behavior is noted:

- Silver. SiC is the main retention barrier, but the kernel is also slightly retentive. Considering the dimensions of the TRISO particle, the diffusion time through the kernel is not negligible compared to the diffusion time through the $\mathrm{SiC}$ layer.

- Cesium. As with silver, the $\mathrm{SiC}$ layer is the main retention barrier, but to a much larger extent than the kernel. However, the kernel is more retentive of cesium than it is silver, which is an important factor in the case of particles with failed SiC layers. Because of its lower diffusivities, cesium exhibits greater retention by both the kernel and the $\mathrm{SiC}$ layer than silver.

- Strontium. Unlike cesium and silver, strontium is primarily retained by the kernel itself, even at high temperature. The combination of a longer diffusion distance in the kernel and a lower diffusivity compared to the $\mathrm{SiC}$ layer makes the kernel the main retention barrier. Therefore, strontium release is less affected by a failure of the SiC layer. 
- Krypton. The peculiarity of krypton is that every part of the TRISO particle (kernel, PyC, $\mathrm{SiC}$ ) acts as a retention barrier. This makes krypton the fission product of choice to detect particle failures, as any release of krypton would mean that all three coating layers have failed, leading to an exposed kernel.

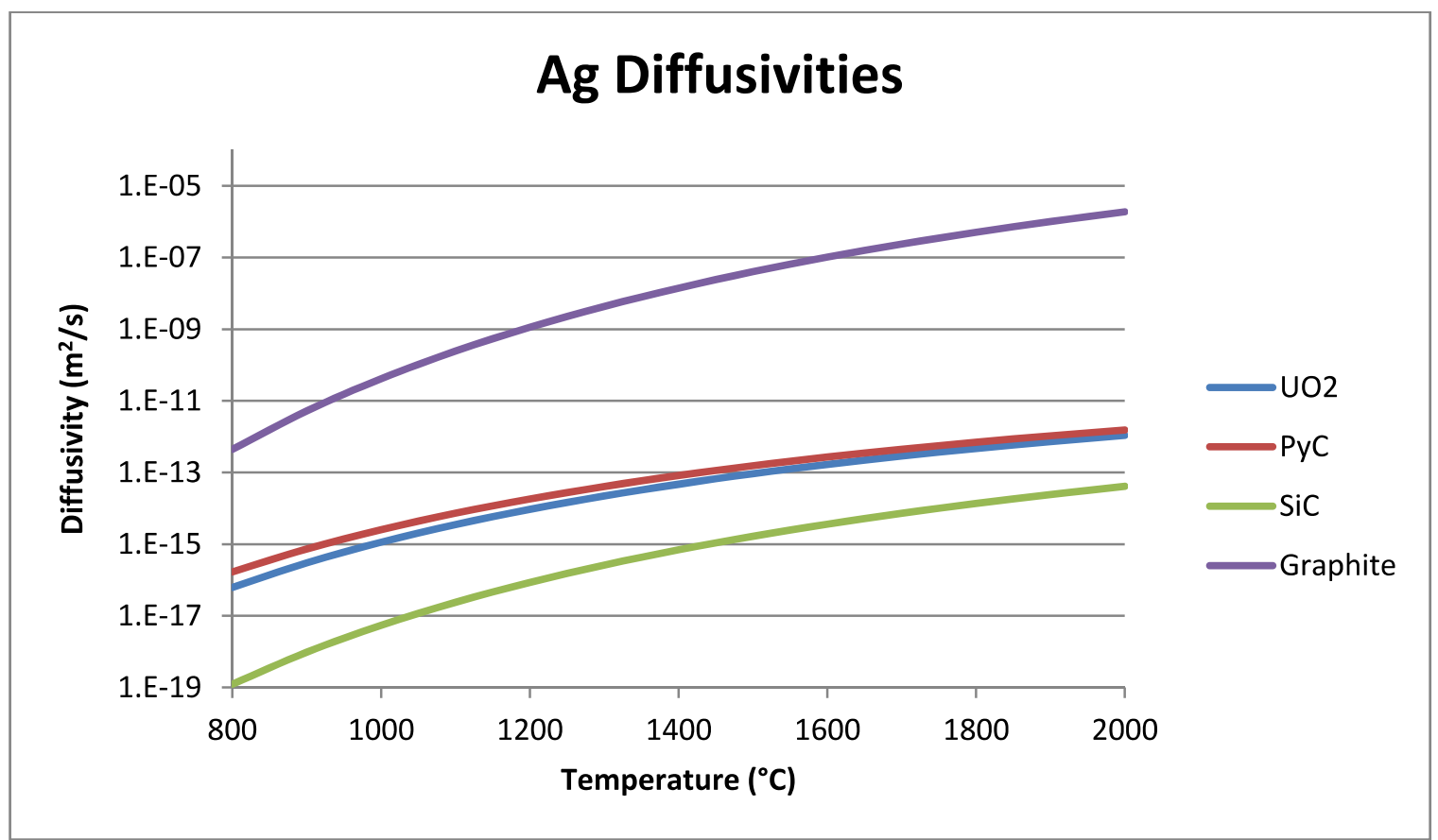

Figure 6. Silver diffusivities.

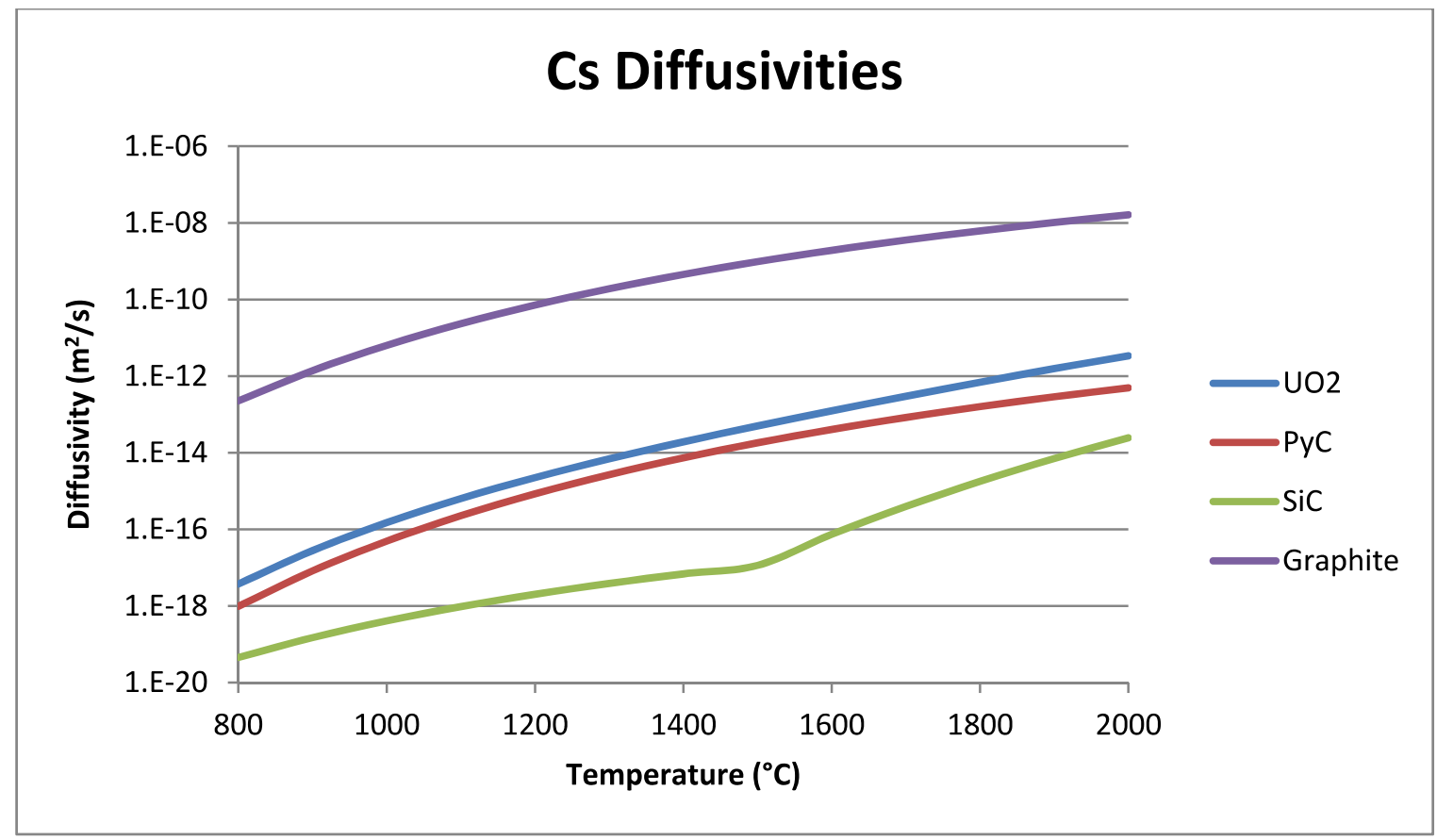

Figure 7. Cesium diffusivities. 


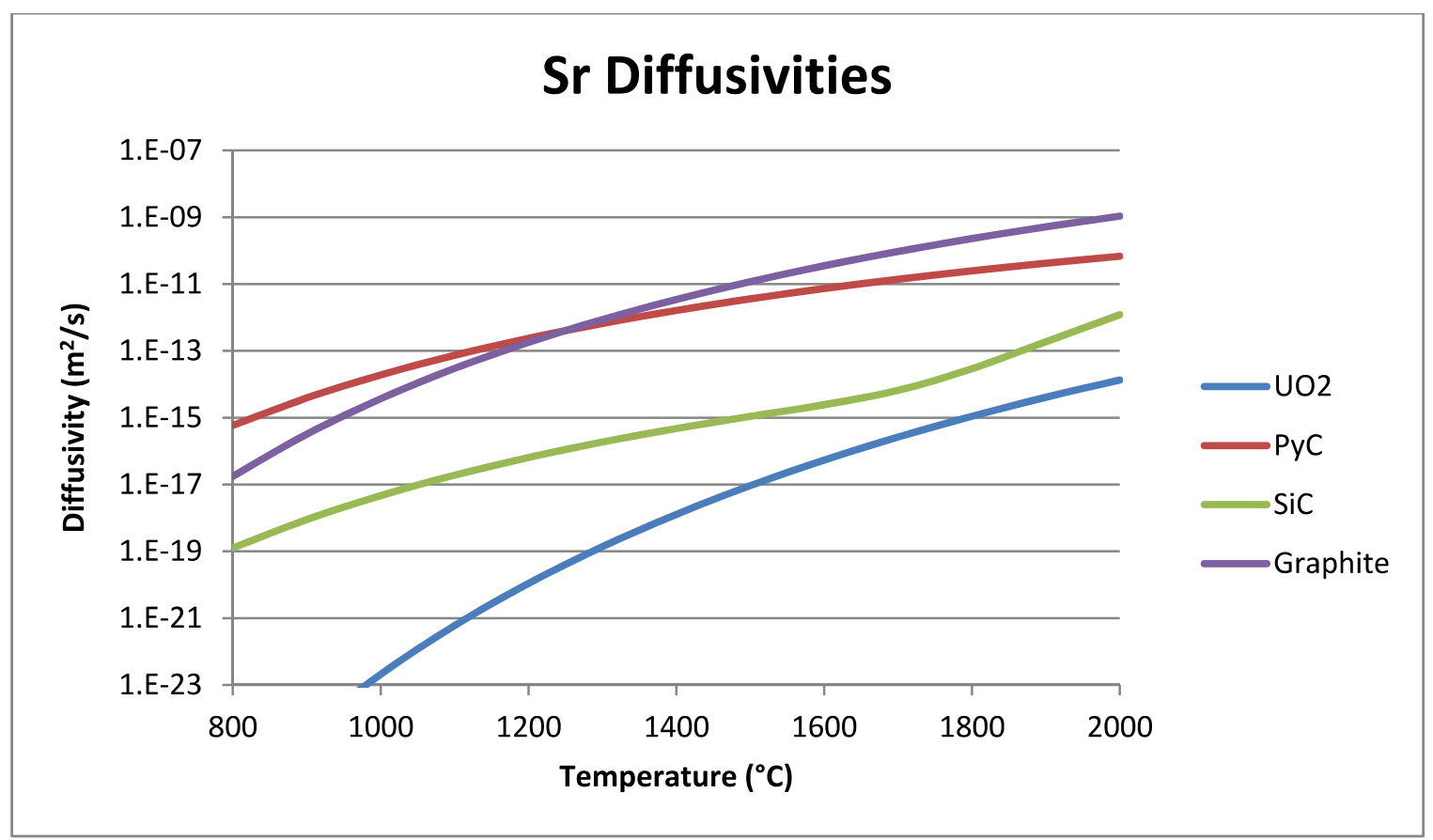

Figure 8. Strontium diffusivities.

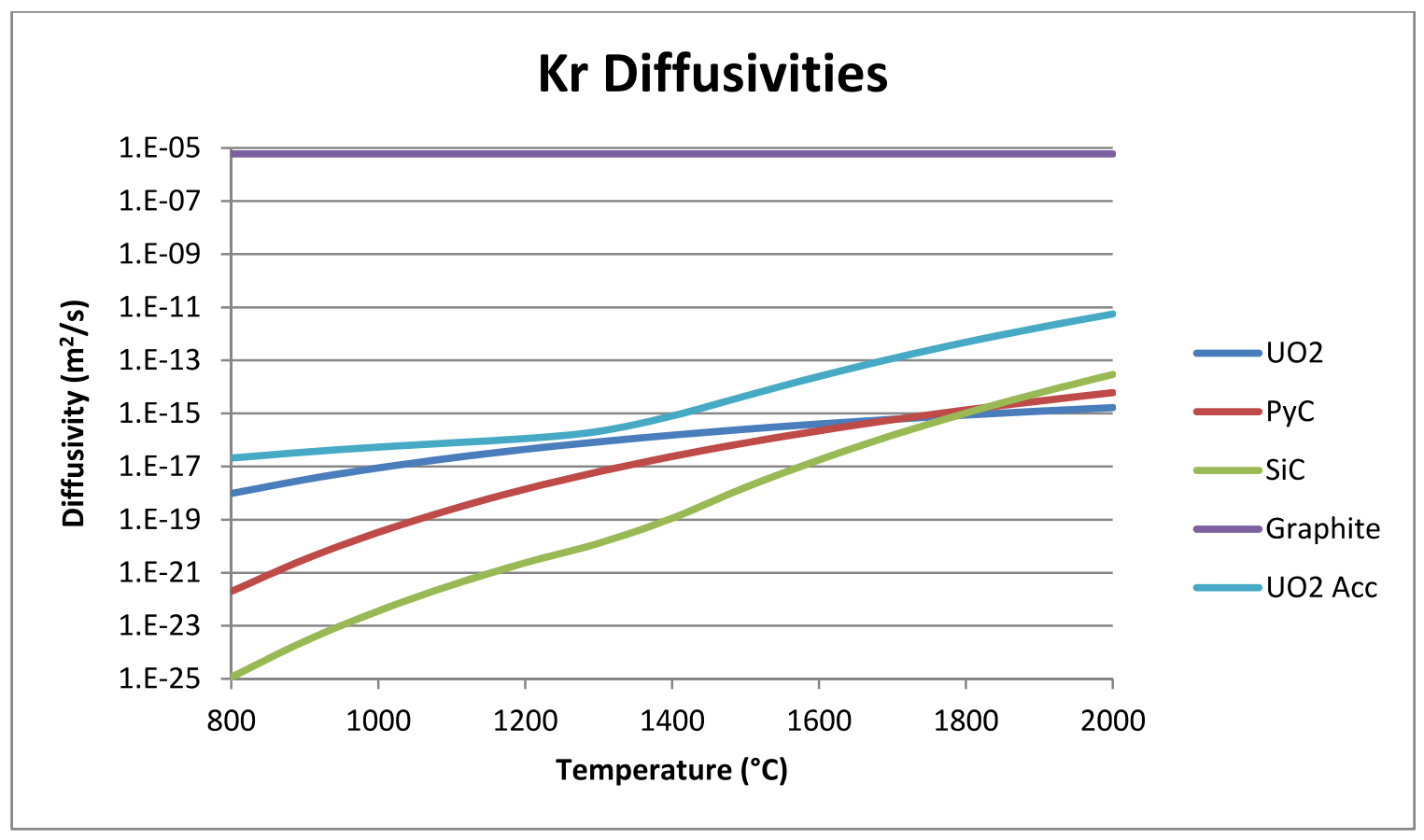

Figure 9. Krypton diffusivities (UO2 Acc denotes the values used during accidental phase).

The release of fission products is calculated at the compact level after the fission products are transported through the TRISO particle and the surrounding compact, and subsequently released from the compact. The fractional release of fission products is then calculated by normalizing the calculated release from the compact to the calculated kernel source.

In PARFUME, the calculation of fission product transport through a collection of particles is weighted by the probability of failure of these particles. The statistical variations in the modeling 
parameters of Table 2 (see Section 3.3) are used to determine any layer failure, at which point the diffusivity of that layer is set to $10-6 \mathrm{~m} 2 / \mathrm{s}$, corresponding to a loss of retentive capability. This relies on the strong assumption that a failed layer does not retain diffusing species at all, even partially, and it is implemented as such for lack of a better understanding of the diffusion mechanisms in failed layers. The resulting release from the collection of particles includes release from intact particles as well as release from particles with failed layers as determined by the stress analysis. To decouple the stress and fission product transport calculations, PARFUME can also be set to inhibit the calculation of failures originating from multi-dimensional effects, which in this study are the main contributors to particle failure. The code can then be modified to separately model intact particles and particles with failed coating layers in the TRISO fuel, by setting the diffusivities of fission products in these layers to the same value of $10-6 \mathrm{~m} 2 / \mathrm{s}$. This results in separate release fractions from intact particles and from particles with failed layers, which can then be combined to compare with experimental data. Furthermore, the modeling of particles with failed layers can be limited to the irradiation phase or the heating phase, or applied to both phases. For cesium and strontium, the IPyC layer is not very retentive, and there is a negligible difference in release from a particle with failed $\mathrm{SiC}$ and intact IPyC and a particle with both layers failed. In this study, PARFUME models the fission product release from both intact particles and particles with both failed IPyC and SiC layers. For simplicity, the failures of the coating layers are assumed to occur at the beginning of the heating phase. 


\section{FISSION PRODUCT RELEASE}

As mentioned in Section 3.4, fission product release is modeled for both intact particles and particles with both failed IPyC and SiC layers. Based on PIE measurements after the safety tests, the number of particles with failed $\mathrm{SiC}$ was assessed and reported in Table 4 . The numbers reported in Table 4 were then used to model the compacts containing particles with failed $\mathrm{SiC}$ layers to allow comparison with the release data.

Table 4. Compacts containing particles with failed SiC layers.

\begin{tabular}{|c|c|c|c|c|c|}
\hline Compact $^{(a)}$ & $\begin{array}{c}\text { Number of } \\
\text { particles with failed } \\
\text { IPyC \& SiC }\end{array}$ & $\begin{array}{c}\text { Safety Test } \\
\text { Temperature }\left({ }^{\circ} \mathbf{C}\right)\end{array}$ & Compact & $\begin{array}{c}\text { Number of } \\
\text { particles with failed } \\
\text { IPyC \& SiC }\end{array}$ & $\begin{array}{c}\text { Safety Test } \\
\text { Temperature }\left({ }^{\circ} \mathbf{C}\right)\end{array}$ \\
\hline $\mathbf{6 - 4 - 3}$ & 0 & 1600 & $\mathbf{4 - 3 - 3}$ & 0 & 1600 \\
\hline $\mathbf{6 - 4 - 1}$ & 1 & 1600 & $\mathbf{4 - 3 - 2}$ & $\mathbf{5}^{(\mathrm{b})}$ & 1800 \\
\hline $\mathbf{6 - 2}-\mathbf{1}$ & 0 & 1600 & $\mathbf{4 - 1 - 2}$ & 1 & 1600 \\
\hline $\mathbf{5 - 3 - 3}$ & 0 & 1600 & $\mathbf{3 - 3}-2$ & 1 & 1600 \\
\hline $\mathbf{5 - 1 - 3}$ & 7 & 1800 & $\mathbf{3 - 3}-1$ & 4 & 1700 \\
\hline $4-4-3$ & 0 & 1700 & $\mathbf{3 - 2}-3$ & 11 & 1800 \\
\hline $4-4-1$ & 2 & 1800 & $\mathbf{3 - 2}-2$ & 0 & 1600 \\
\hline
\end{tabular}

a. Compacts heated-up at $1600^{\circ} \mathrm{C}$ are highlighted in blue, at $1700^{\circ} \mathrm{C}$ in green, and at $1800^{\circ} \mathrm{C}$ in red.

b. Compact 4-3-2 was determined to have two TRISO failures.

Table 4 shows that about half of the compacts heated-up to 1600 and $1700^{\circ} \mathrm{C}$ contain particles whose $\mathrm{SiC}$ layers failed during the safety tests. All the compacts heated-up to $1800^{\circ} \mathrm{C}$ have particles with failed $\mathrm{SiC}$ layers. Compact 4-3-2 was determined to have two TRISO failures; therefore, it is modeled using three particles with both failed IPyC and SiC layers and two particles with exposed kernels.

Sections 4.1 to 4.4 present the comparisons on fission product release between PARFUME and PIE for silver, cesium, strontium, and krypton, respectively. For each species, the results are split into two histograms: one histogram showing the release fractions from compacts containing only intact particles, and one histogram showing the release fractions from compacts containing particles with failed coating layers. The compact labels are indicated on the x-axis with the same color coding as used in Table 4 . The magnitude of the release from intact particles varies depending on the fission product: PARFUME calculates that silver and strontium will be released from intact particles, while cesium and krypton are essentially well retained in intact particles. For this reason, in the histograms showing the release fractions from compacts containing particles with failed coatings, the predicted release fractions include the contribution from intact particles in the case of silver and strontium, but they exclude the contribution from intact particles in the case of cesium and krypton.

\subsection{Silver Release}

Figures 10 and 11 show the fractional release of silver from compacts containing only intact particles and from compacts containing particles with failed SiC layers, respectively. The safety test release data correspond to the amount of silver released from the compacts and measured during the entire duration of the safety tests. In particular, they include silver released during the first $\sim 24$ hours of the tests, which is believed to be silver retained in the matrix, or possibly in the OPyC layer, at the end of the irradiation phase (Morris 2014). The prompt release of silver when the compacts are heated to high temperature, followed by a smoother slower release, tends to indicate that the early release is not from the particles but rather from the matrix. Therefore, this suggests that this silver was present outside of the SiC layer at the end of the AGR-1 irradiation, and was then rapidly released once the compacts were brought to 
temperatures above $1600^{\circ} \mathrm{C}$. Consequently, the fractional release during the heating phase is assumed to be obtained by considering the amount of silver released after the first 24 hours of the test.

Figures 12 and 13 show the fractional release of silver corrected to exclude release during the first 24 hours of the safety tests. In the case of modeling, there is no difference in the calculated fractional release because PARFUME does not predict any silver retention in the OPyC layer or compact matrix. Compacts 3-2-2 and 3-2-3 were subject to unplanned temperature ramps at the beginning of their respective safety tests that caused some silver release, which is believed to be from intact particles and not from silver outside the $\mathrm{SiC}$ at the end of irradiation. For these compacts, the correction associated to the matrix content is dubious at best. It is still included in this study for the sake of completeness and because including these compacts in the analysis does not impact its conclusions.

Comparison of safe-testing data between Figures 12 and 13 shows that the release is associated with intact particles. The release from compacts containing particles with failed $\mathrm{SiC}$ (Figure 13) is similar to the contribution from compacts containing only intact particles (Figure 12), when data at similar temperatures $\left(1600\right.$ and $\left.1700^{\circ} \mathrm{C}\right)$ are compared. Because of the high release from intact particles, silver release from failed particles cannot be discerned.

Figure 12 shows that the release from compacts containing only intact particles is overpredicted 2 to 3.5 orders of magnitude at $1600^{\circ} \mathrm{C}$ and 2.5 orders of magnitude at $1700^{\circ} \mathrm{C}$. The overprediction is 2.5 to 3.5 orders of magnitude at $1600^{\circ} \mathrm{C}$ for compacts containing particles with failed $\mathrm{SiC}$, while at $1700^{\circ} \mathrm{C}$ it essentially remains at 2.5 orders of magnitude (see Figure 13). At $1800^{\circ} \mathrm{C}$ the overprediction is by 1 to 2 orders of magnitude for compacts containing particles with failed $\mathrm{SiC}$, but PARFUME predicts that all of the remaining silver is released during heating, which means the total release fraction is close to $100 \%$ when the silver released during irradiation is accounted for.

At 1600 and $1700^{\circ} \mathrm{C}$, the overprediction is the same order of magnitude for compacts with only intact particles and compacts containing particles with failed coating layers. With the modeling assumptions, the diffusion of silver through a particle with failed $\mathrm{SiC}$ is controlled by the diffusivity in the kernel, while it is controlled by both diffusivities in the kernel and in the $\mathrm{SiC}$ through an intact particle. The overpredictions observed in Figures 12 and 13 indicate that the diffusivity in the $\mathrm{SiC}$ is significantly overestimated because the dominant release from intact particles is largely overpredicted. A potential overestimation of the diffusivity in the kernel does not impact the calculated release from intact particles because the $\mathrm{SiC}$ layer is the last barrier before release. Therefore, an overestimation of the diffusivity in the $\mathrm{SiC}$ can only explain the overprediction of the release from intact particles. It could be argued that an overestimation of the diffusivity in the kernel would further increase the overprediction of the release in compacts containing particles with failed $\mathrm{SiC}$ and that, conversely, the absence of increase of the overprediction between Figures 12 and 13 implies that the diffusivity in the kernel is correctly modeled. But, because the overall release is largely dominated by the release from intact particles, the overprediction of the release from particles with failed $\mathrm{SiC}$, or lack thereof, cannot be established definitively. Since the $\mathrm{SiC}$ layer is the main barrier to silver diffusion, it is assumed that the overprediction is solely caused by an overestimation of the diffusivity in $\mathrm{SiC}$ and that the diffusivity in the kernel is, at best, correctly modeled.

Figure 14 shows the impact of a reduction in the diffusivity of silver in $\mathrm{SiC}$ on the calculated release fractions from intact particles at 1600,1700 , and $1800^{\circ} \mathrm{C}$. The IAEA diffusivity was divided by successive powers of ten and the subsequent release fractions were calculated at all three safety testing temperatures. Also shown on the plot are the maximum measured release fractions that are obtained from all 14 heating tests since silver release is dominated by intact particles even in compacts containing particles with failed $\mathrm{SiC}$. The maximum release fractions at each temperature are used to obtain upper limits of the measured release, which subsequently leads to upper limits for the diffusivity of silver in $\mathrm{SiC}$. The intersection of the curves of the diffusivity-dependent release fractions with the maximum measured release fractions provide a minimum estimate of how much the diffusivities in $\mathrm{SiC}$ need to be 
reduced for the calculated release fractions to match PIE measurements. At 1600 and $1700^{\circ} \mathrm{C}$, the correction factor is close to $10^{3}$, and it is between 10 and $10^{2}$ at $1800^{\circ} \mathrm{C}$.

The PIE data at $1700^{\circ} \mathrm{C}$ consist of one release fraction result per each category of compactcontaining either intact particles only or particles with failed SiC. Because of the measurement uncertainty on release fractions and the lack of statistical significance, the correction factor at $1700^{\circ} \mathrm{C}$ is a gross estimate. Compacts 4-4-3 and 3-3-1 were still included in the analysis for the sake of completeness, but the resulting correction factors should be considered with care.

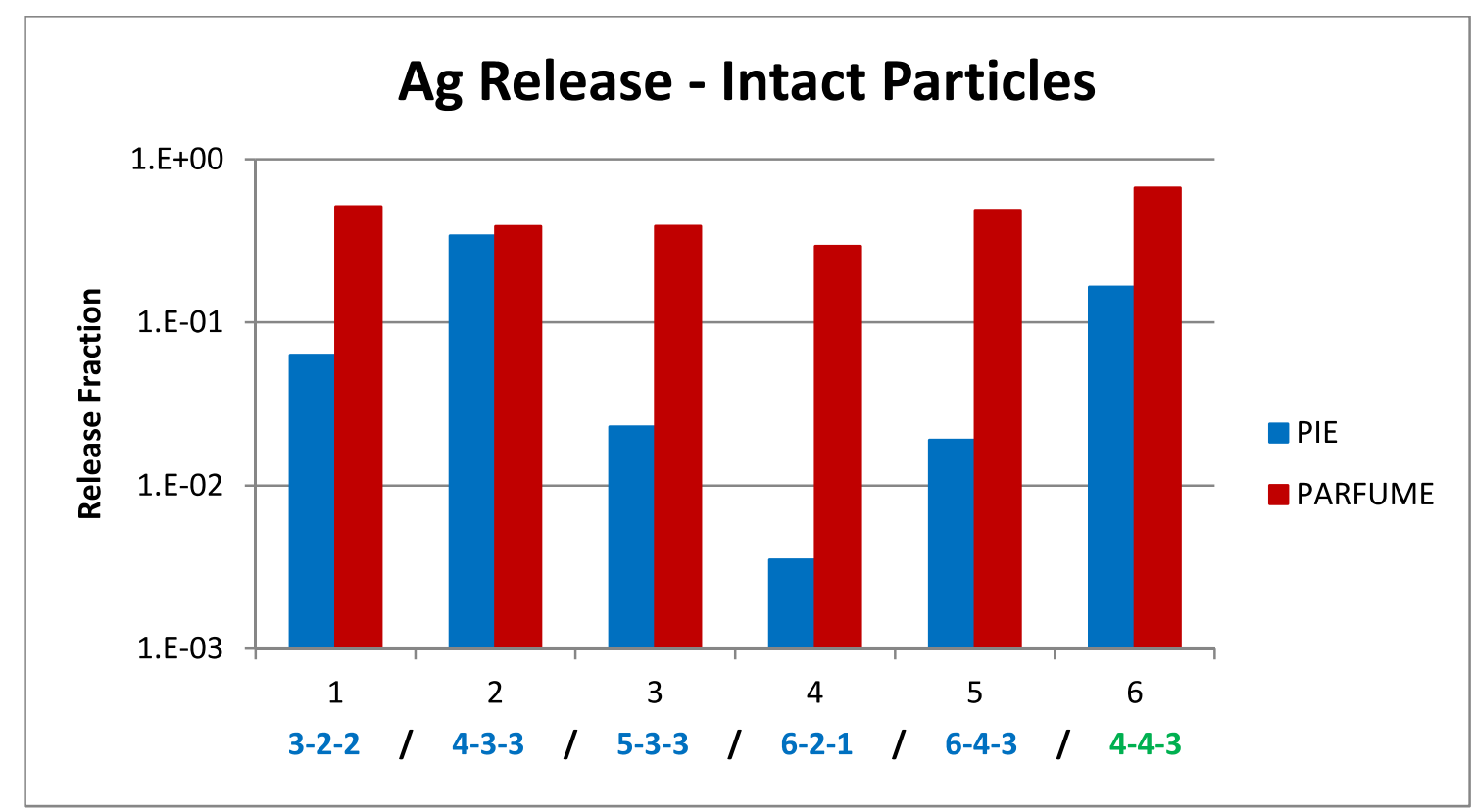

Figure 10. Silver fractional release from compacts containing only intact particles.

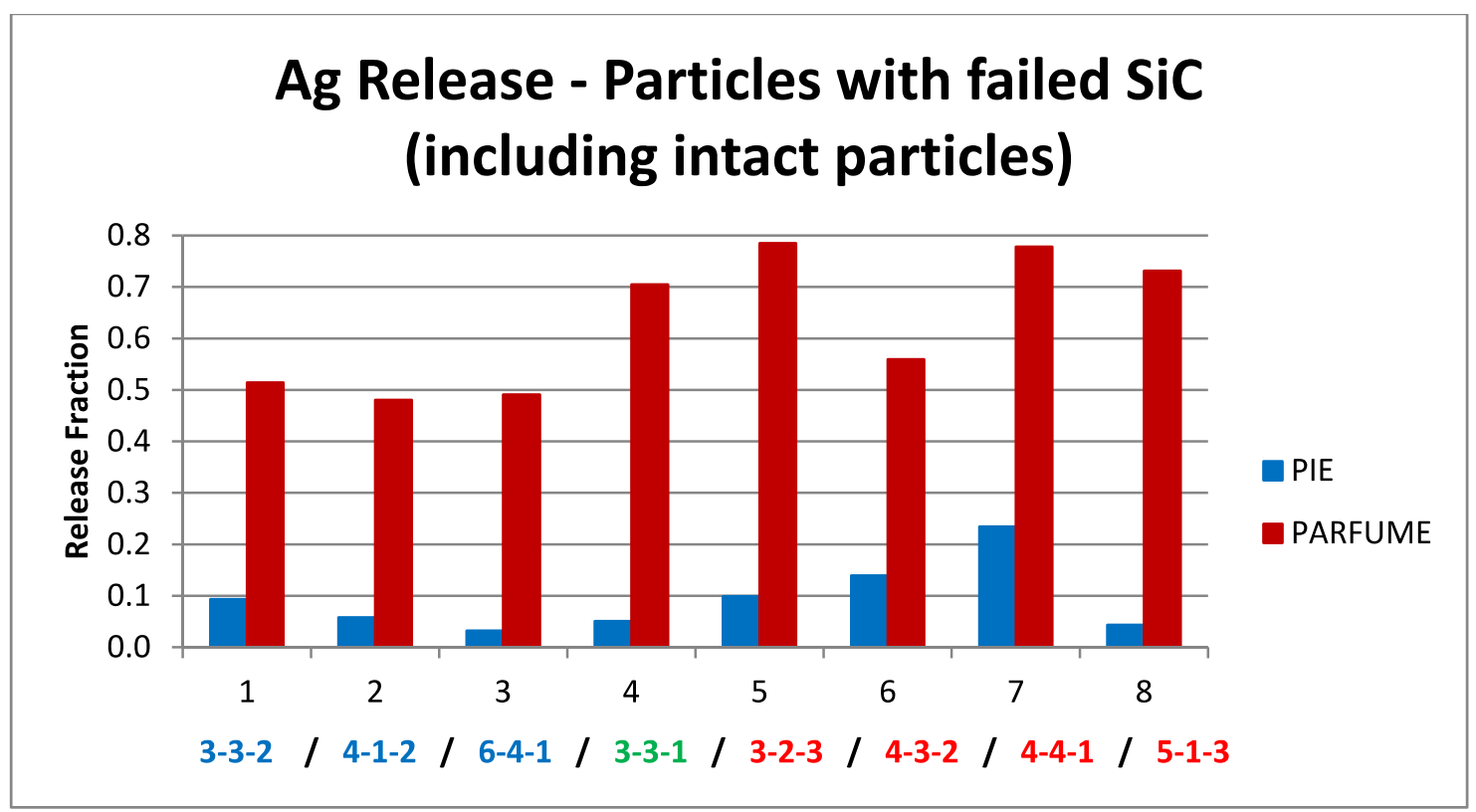

Figure 11. Silver fractional release from compacts containing particles with failed SiC layers. PARFUME predictions include the release from intact particles. 


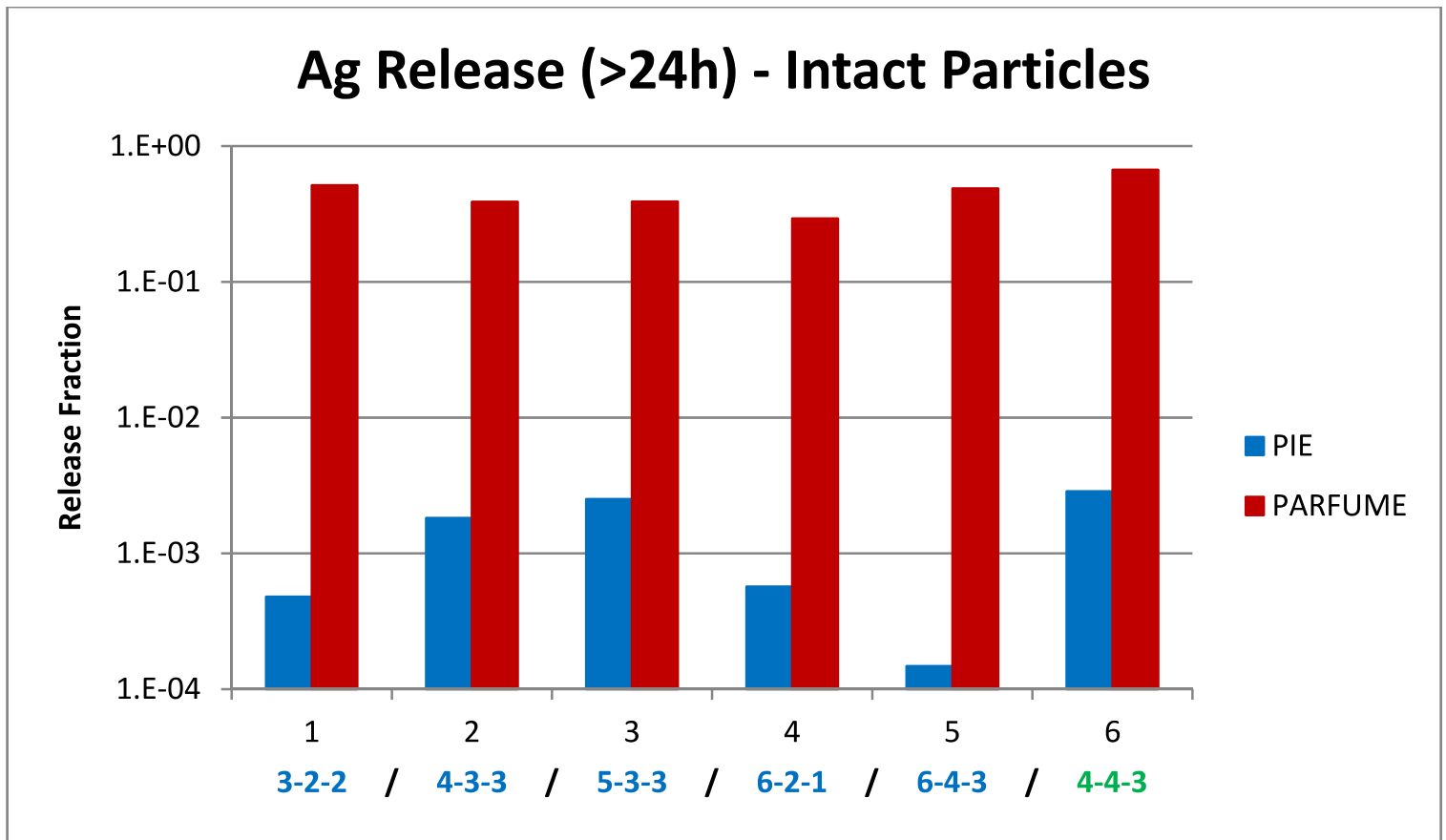

Figure 12. Silver fractional release from compacts containing only intact particles corrected to exclude release during the first $\sim 24$ hours of the safety tests.

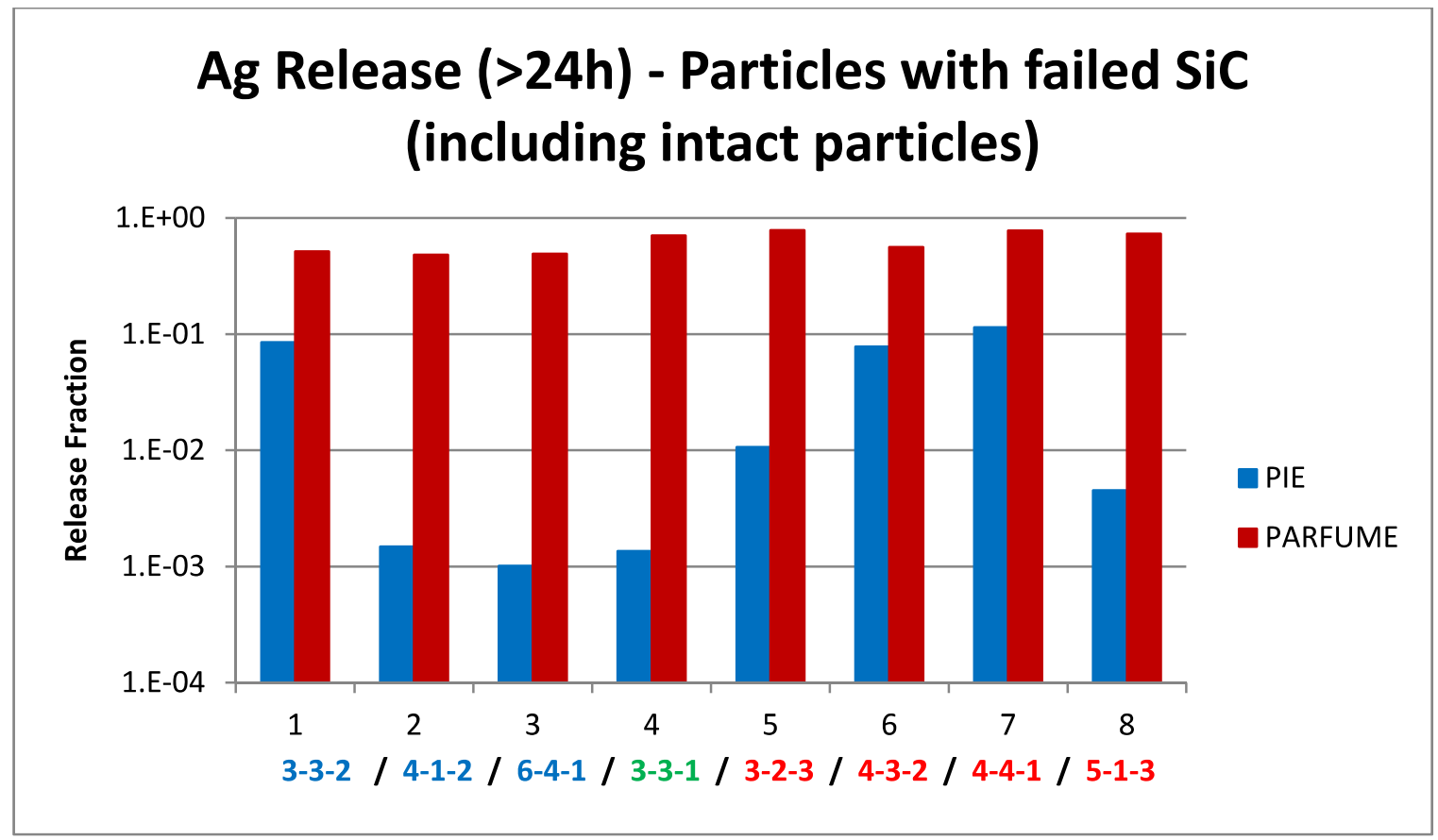

Figure 13. Silver fractional release from compacts containing particles with failed $\mathrm{SiC}$ layers corrected to exclude release during the first $\sim 24$ hours of the safety tests. PARFUME predictions include the release from intact particles. 


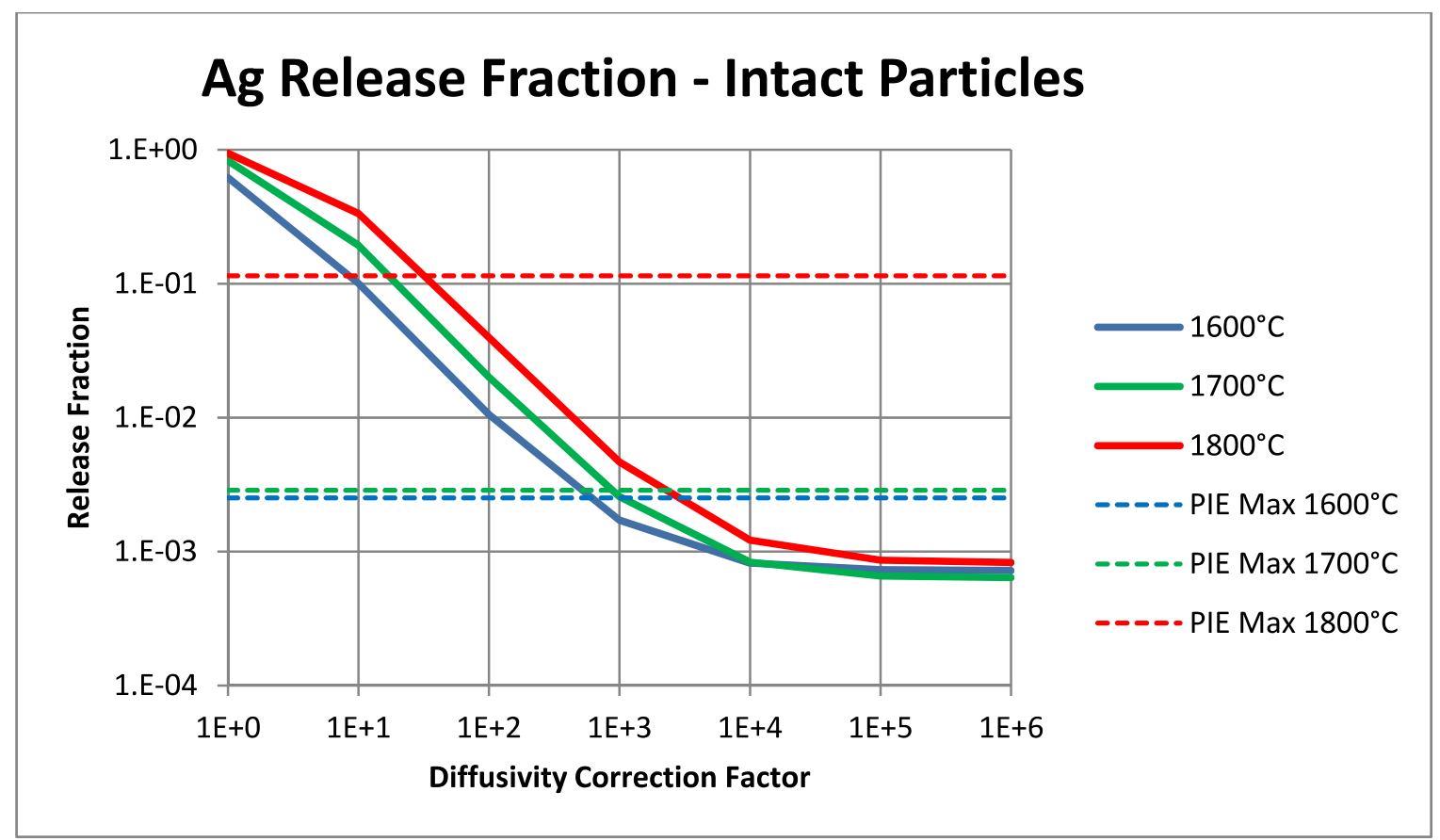

Figure 14. Calculated silver release fraction versus diffusivity in $\mathrm{SiC}$ during safety testing.

\subsection{Cesium Release}

Figures 15 and 16 compare the calculated and measured fractional releases of cesium for compacts containing only intact particles and compacts containing particles with failed $\mathrm{SiC}$ layers, respectively.

Figure 15 shows that the measured release from intact particles is limited. Moreover, it is overpredicted by PARFUME by 3 to 4 orders of magnitude at $1600^{\circ} \mathrm{C}$ and 5.5 orders of magnitude at $1700^{\circ} \mathrm{C}$. It is suspected that a significant portion of this release is from inventory outside the $\mathrm{SiC}$ at the end of irradiation (Morris 2014), which would mean that the release from intact particles would be even lower than shown in Figure 15, and the overprediction by PARFUME even larger.

For compacts containing particles with failed SiC, Figure 16 shows a fairly good agreement between safety testing data and PARFUME, when considering no release from the intact particles in the PARFUME predictions. Comparisons between PIE (blue bars) and the predicted release from the particles with failed coating layers (red bars) give overpredictions of factors of up to 2 at $1600^{\circ} \mathrm{C}, 3$ at $1700^{\circ} \mathrm{C}$, and 1.5 at $1800^{\circ} \mathrm{C}$. This would indicate that the diffusivity in the kernel is somewhat overestimated, because the release from a particle with a failed SiC layer is controlled by the diffusivity in the kernel since the PyC layers are non-retentive to cesium.

As an example, Compact 6-4-1 has a measured release fraction of 1.2 10 10-4, while PARFUME predicts $100 \%$ release from the kernel and from the failed $\mathrm{SiC}$ layer. With one failed particle in the compact that contains $\sim 4150$ particles, this corresponds to a calculated release fraction of $2.4 \times 10-4$. Therefore, the overprediction is a factor of 2 . To match safety testing data, the calculation theoretically needs a reduction in the diffusivity of cesium in the kernel that brings its release fraction to $50 \%$. Figure 17 shows the impact of a reduction of the diffusivity of cesium in the kernel on the calculated release fractions from the kernel at 1600,1700 , and $1800^{\circ} \mathrm{C}$. At all three temperatures, the release fractions approach $\sim 75 \%$ when the diffusivity is decreased. This means that around $75 \%$ of the cesium is outside of the kernel at the end of irradiation. Consequently, reducing the diffusivity of cesium in the kernel during the safety test does not reduce the discrepancy between PARFUME and PIE. The release fraction is limited to $\sim 75 \%$ because of the calculated release during irradiation. As a consequence, the 
gain of $25 \%$ (from a calculated release of $\sim 100 \%$ with the IAEA diffusivity to about $75 \%$ when that diffusivity is reduced) cannot account for the factors of 2, 3, and 1.5 required for PARFUME to match PIE at the three safety testing temperatures.

Comparisons between PIE and PARFUME on cesium release at the end of irradiation showed that the diffusivity of cesium in the kernel during irradiation might actually be overestimated by a factor of about 100 (Collin 2014b). Figure 18 shows the impact of a reduction in the diffusivity of cesium in the kernel on the calculated release fractions from the kernel at 1600,1700 , and $1800^{\circ} \mathrm{C}$, when the diffusivity in the kernel is reduced by a factor of 100 during irradiation. Figure 18 shows that the resulting fraction of cesium outside the kernel at the end of irradiation drops from around $75 \%$ to about $35 \%$. Figure 18 also includes the maximum measured release fractions from the kernel at each safety test temperature, which are used as targets to reduce the diffusivity of cesium in the kernel so that PARFUME results would match PIE measurements. For example, in the case of compacts heated up at $1600^{\circ} \mathrm{C}$, the larger discrepancy between measured data and PARFUME calculations is for Compact 6-4-1 with an overprediction of a factor of 2 (i.e., the calculated release has to be reduced to $50 \%$ to have PARFUME match PIE). The intersection of the curves of the diffusivity-dependent release fractions and of the release fraction targets indicate that the diffusivities in the kernel need to be reduced between at least $10^{2}$ and $10^{3}$ at $1600^{\circ} \mathrm{C}$, at least $10^{5}$ at $1700^{\circ} \mathrm{C}$, and approximately $10^{3}$ at $1800^{\circ} \mathrm{C}$ for the calculated release fractions to match PIE measurements. Note that the analysis is run on only one data point at $1700^{\circ} \mathrm{C}$ (Compact 3-3-1), which limits the accuracy of the analysis. As with silver, because of the lack of statistical significance of the PIE data at $1700^{\circ} \mathrm{C}$, the correction factor at $1700^{\circ} \mathrm{C}$ should be considered with care.

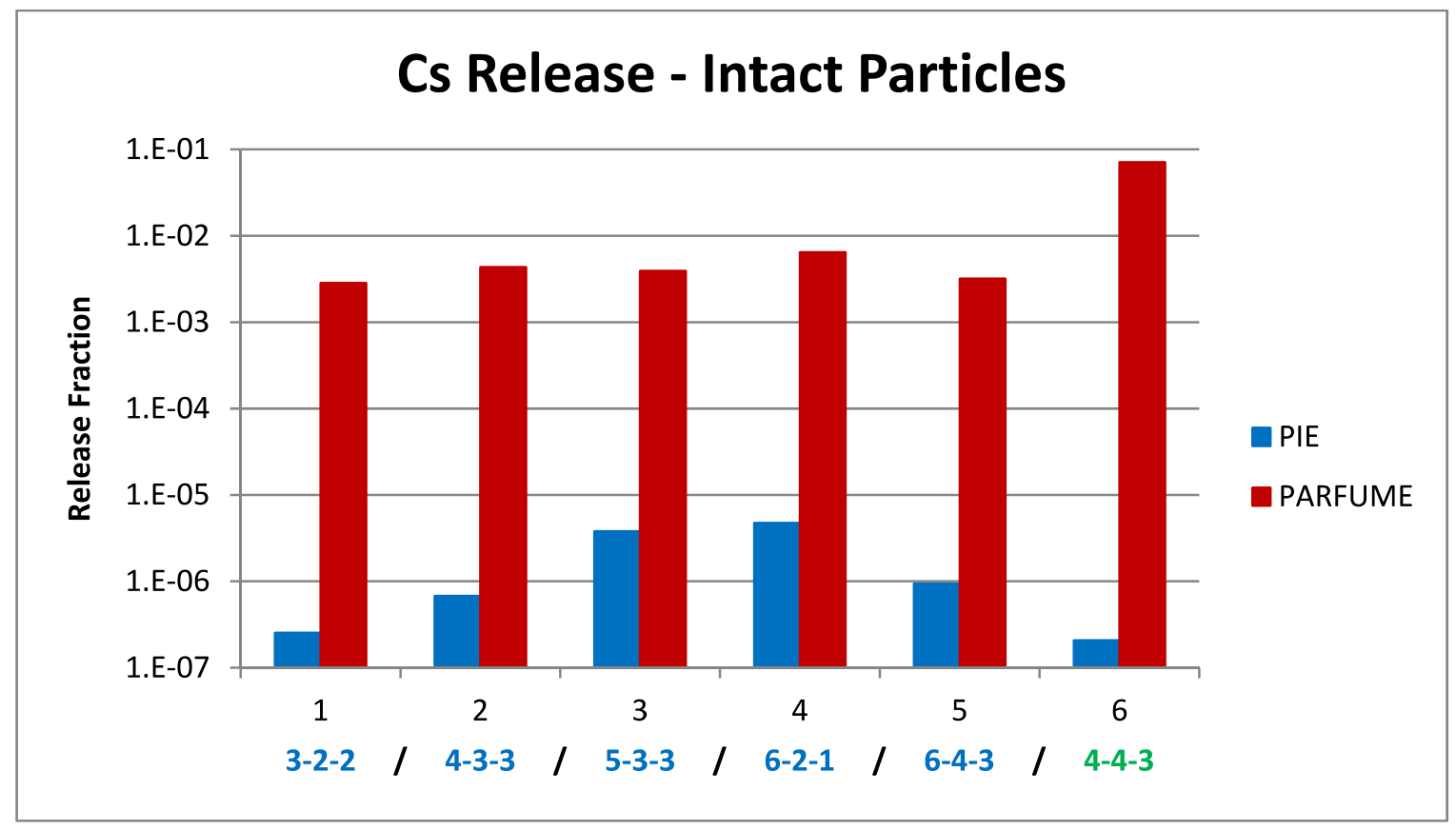

Figure 15. Cesium fractional release from compacts containing only intact particles. 


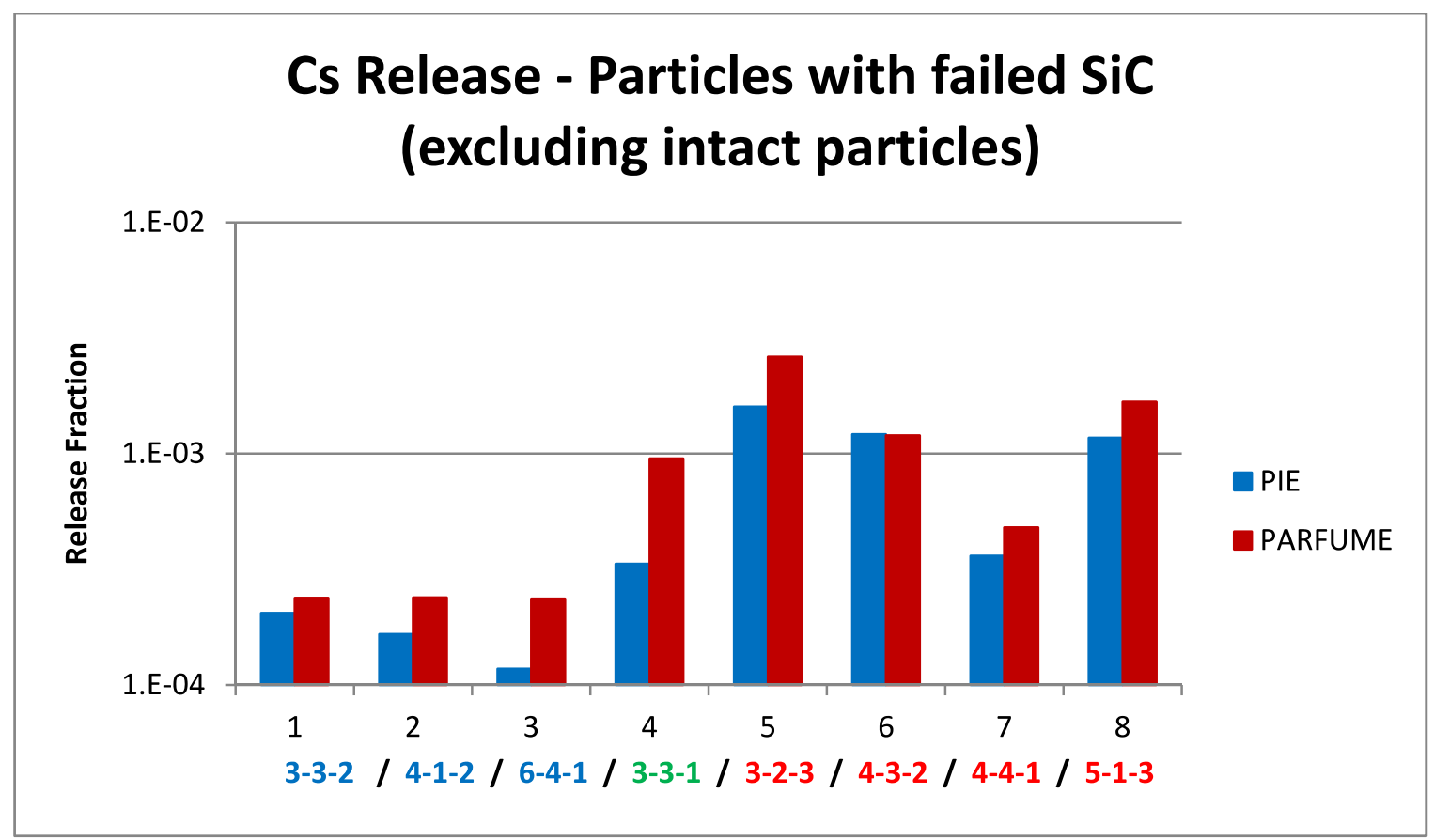

Figure 16. Cesium fractional release from compacts containing particles with failed SiC layers. PARFUME predictions exclude the release from intact particles.

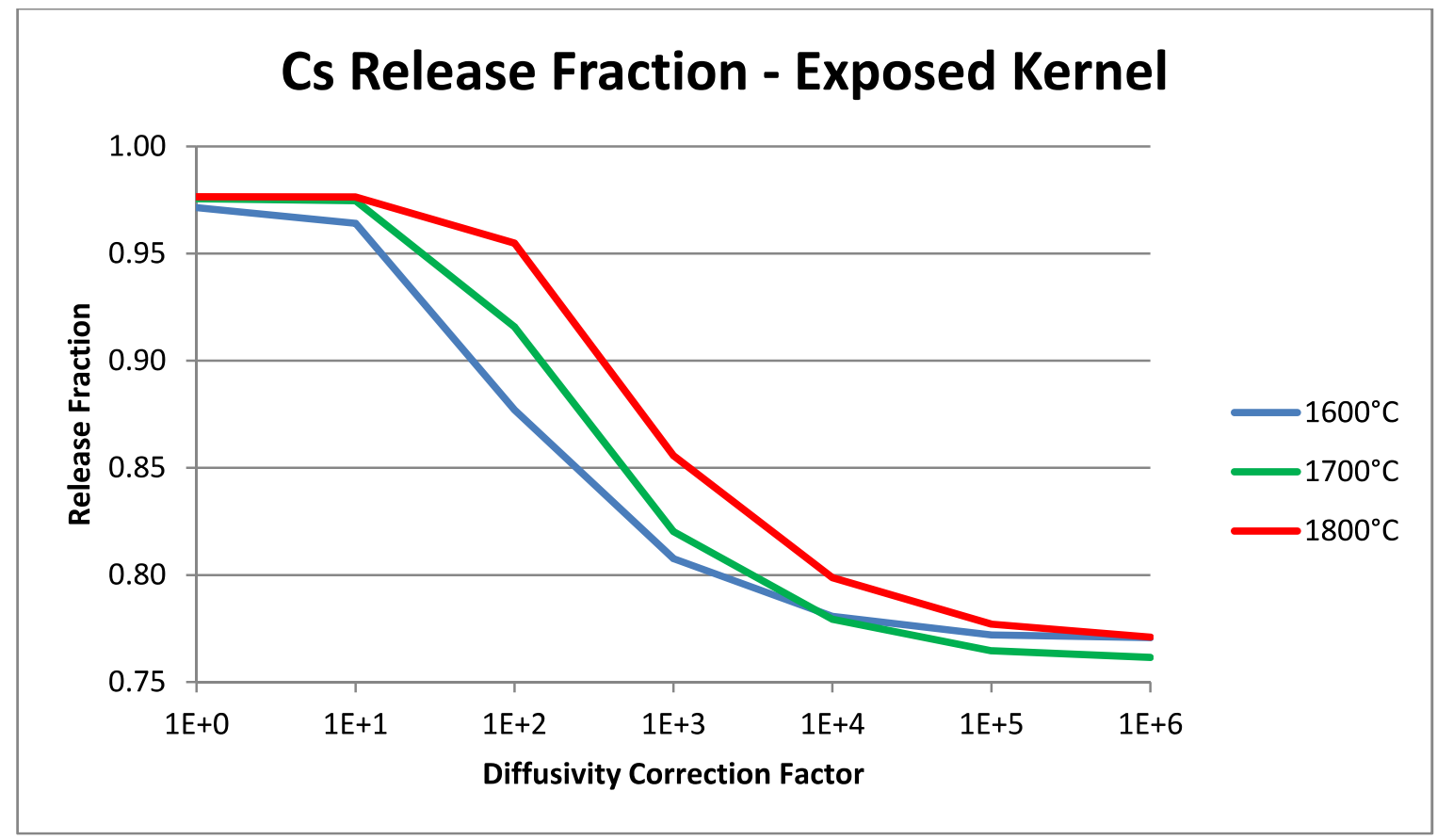

Figure 17. Calculated cesium release fraction versus diffusivity in the kernel during safety testing. 


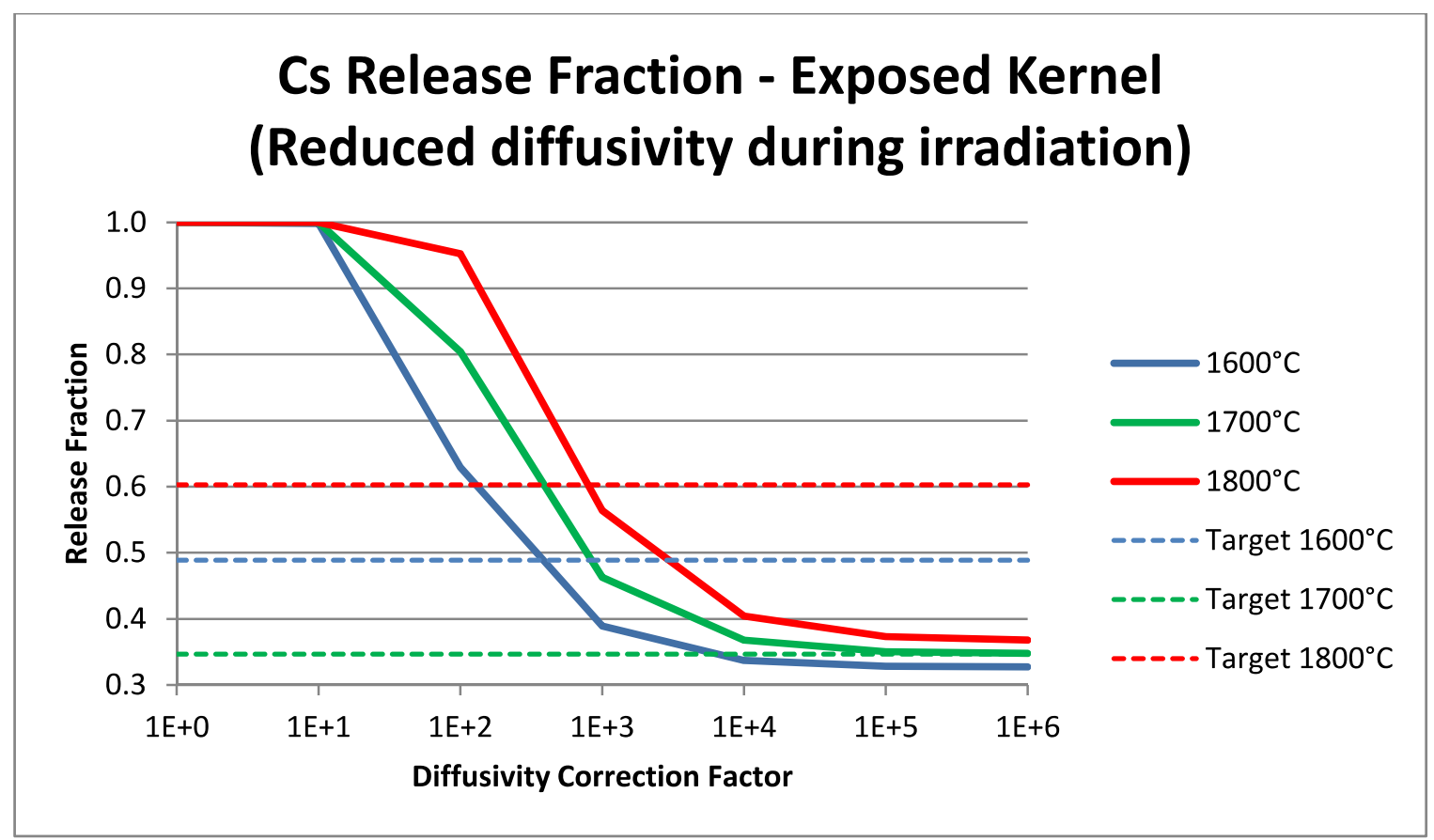

Figure 18. Calculated cesium release fraction versus diffusivity in the kernel during safety testing. The diffusivity of cesium in the kernel during irradiation was reduced by a factor of 100 .

In addition to the overestimation of the diffusivity of cesium in the kernel during irradiation by a factor of 100, comparisons between PIE and PARFUME also showed that the diffusivity of cesium in SiC during irradiation could be overestimated by about 30\% (Collin 2014b). When these two corrections are taken into account, calculations show that the overprediction of the release from intact particles in heating tests shown in Figure 15 cannot be explained by the overestimated diffusivity in the kernel alone, and an overestimation of the diffusivity of cesium in the SiC layer must also be accounted for. From Figure 18, the correction factors for the diffusivity of cesium in the kernel were set to 500 at $1600^{\circ} \mathrm{C}$ and to $10^{5}$ at $1700^{\circ} \mathrm{C}$. There was no analysis made at $1800^{\circ} \mathrm{C}$ since all the compacts tested at this temperature contain particles with failed $\mathrm{SiC}$ layers whose release largely dominates the release from the compact and obscures any release from intact particles.

Combining all three corrections on the respective diffusivities (in the kernel under irradiation, in SiC under irradiation and in the kernel under heating test conditions), Figure 19 shows the impact of a reduction in the diffusivity of cesium in $\mathrm{SiC}$ during heating tests on the calculated release fractions from intact particles at 1600 and $1700^{\circ} \mathrm{C}$. The maximum measured release fractions at each temperature are also plotted in Figure 19, and they are used to obtain upper limits of the measured release fractions. The intersections of the curves of the diffusivity-dependent release fractions and of the maximum measured release fractions show that the diffusivities in $\mathrm{SiC}$ need to be reduced at least by a factor of 10 at $1600^{\circ} \mathrm{C}$ and a factor of about $10^{3}$ at $1700^{\circ} \mathrm{C}$ for the calculated cesium release fractions from intact particles under accident heating tests to match PIE measurements. The correction factor at $1700^{\circ} \mathrm{C}$ is again based on one release fraction result only (Compact 4-4-3), which limits its reliability.

Figure 19 also shows that a calculated fraction of around $10^{-7}$ of the cesium lies outside the SiC. This fraction corresponds to the production of cesium from uranium contamination (see Table 2 in Section 3.3). A release fraction corresponding to the uranium contamination is obtained when the diffusivity in the $\mathrm{SiC}$ is set at a value that prevents cesium from diffusing through it, and only cesium produced from uranium contamination can then be measured outside of the particle. Figure 15 shows that some compacts have a measured release of the order of magnitude of this uranium contamination, which indicates a high 
retention of cesium by the $\mathrm{SiC}$ layer. It should also be noted that the measured release from intact particles shown in Figure 15 is comparable to the release obtained after irradiation by deconsolidation of selected irradiated compacts and subsequent measurement of the content of cesium outside the $\mathrm{SiC}$ (Collin 2014b). This comparability between release fractions at the end of irradiation and at the end of the safety tests indicates very little to no additional release of cesium during safety testing.

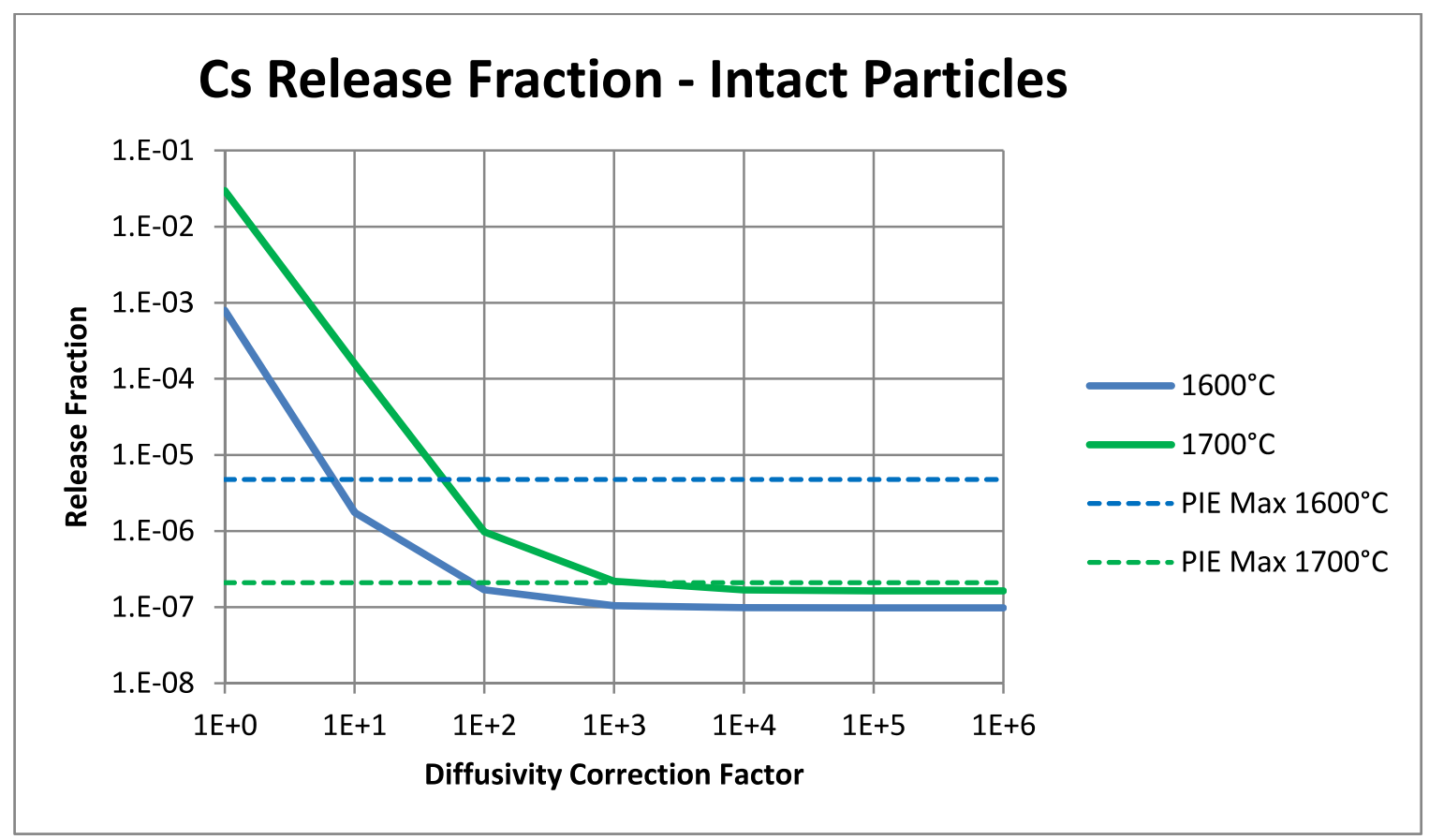

Figure 19. Calculated cesium release fraction versus diffusivity in $\mathrm{SiC}$ during safety testing. The diffusivities of cesium in the kernel and in $\mathrm{SiC}$ during irradiation were reduced by a factor of 100 and by $30 \%$, respectively, and the diffusivity of cesium in the kernel during safety testing was reduced by a factor of 500 at $1600^{\circ} \mathrm{C}$ and 105 at $1700^{\circ} \mathrm{C}$.

\subsection{Strontium Release}

Figures 20 and 21 show the fractional release of strontium for compacts containing only intact particles and compacts containing particles with failed SiC layers, respectively.

Comparison of safety testing data between Figures 20 and 21 shows that, overall, the release is dominated by intact particles. Releases from compacts containing particles with failed SiC (Figure 21) are similar to releases from compacts containing only intact particles (Figure 20), when data at similar temperatures $\left(1600\right.$ and $\left.1700^{\circ} \mathrm{C}\right)$ are compared. Because of the dominant release from intact particles, strontium release from failed particles cannot be discerned.

It is not possible to determine directly if the strontium release measured during safety testing is due to release through intact $\mathrm{SiC}$ or simply from residual inventory outside the $\mathrm{SiC}$ at the end of irradiation. The total inventory of strontium release from the compacts during safety tests at $1600^{\circ} \mathrm{C}$ is similar to the levels found in as-irradiated compacts outside of the $\mathrm{SiC}$ layer. At the end of the safety tests, the amount of strontium outside the $\mathrm{SiC}$ is not negligible compared to the amount collected on the deposition cups in the furnace. Therefore, it is not clear whether any of the strontium released during safety testing is from intact particles, if it simply is due to slow release from strontium already outside of the $\mathrm{SiC}$ at the end of irradiation, or a combination of both. However, the bulk of PIE data suggests that the majority of the strontium release from safety testing is due to inventory residing outside of $\mathrm{SiC}$ at the end of irradiation (Morris 2014). 
Figure 20 shows that the release from intact particles is overpredicted by 2 to 3.5 orders of magnitude at $1600^{\circ} \mathrm{C}$ and 2 orders of magnitude at $1700^{\circ} \mathrm{C}$. For compacts containing particles with failed $\mathrm{SiC}$, the overprediction is by 2 orders of magnitude at 1600,1700 and $1800^{\circ} \mathrm{C}$. The overprediction might be even larger if the measured release does not originate from the particles.

The differences between PARFUME and PIE for release from compacts containing only intact particles or for compacts containing particles with failed SiC are similar. Similarly to the analysis of silver release (see Section 4.1), it is assumed that the overestimation of strontium release is associated with an overestimation of the diffusivity in $\mathrm{SiC}$ and that the diffusivity in the kernel is, at best, correctly modeled.

Comparisons between PIE and PARFUME on strontium release at the end of irradiation showed that the diffusivity of strontium is overestimated in either the kernel or in the $\mathrm{SiC}$ layer, or possibly in both, but the available data do not allow a precise assessment of the effective overestimation of these diffusivities (Collin 2014b). Contrary to the methodology used for the analysis of cesium release, the diffusivities of strontium in the kernel or $\mathrm{SiC}$ during irradiation cannot be corrected. Therefore, the overprediction of strontium release from intact particles during safety testing is assumed to only be caused by an overestimation of the diffusivity of strontium in $\mathrm{SiC}$ during safety testing. This might lead to an overestimation of the correction factors on the diffusivities because any discrepancies in strontium retention during irradiation are not captured by these calculations. In addition, this assumes that the measured release comes from particles rather than the matrix, which is dubious at best, as discussed above. Should any of the measured strontium originate from the matrix, the overprediction would be even larger and the subsequent corrections on the diffusivities would be underestimated. Overall, the uncertainties on both strontium release during irradiation and possible strontium retention by the matrix lead to an approximate assessment of the overprediction of strontium release and to approximate correction factors for the diffusivities of strontium in $\mathrm{SiC}$ at the three safety testing temperatures.

Figure 22 shows the impact of a reduction in the diffusivity of strontium in $\mathrm{SiC}$ on the calculated release fractions from intact particles at 1600,1700 , and $1800^{\circ} \mathrm{C}$. The maximum measured release fractions at each temperature are also plotted in Figure 22, and they are used to obtain upper limits of the measured release fractions. They are obtained from the measured release fractions of all 14 compacts since strontium release is dominated by intact particles even in compacts containing particles with failed $\mathrm{SiC}$. The intersections of the curves of the diffusivity-dependent release fractions and the maximum measured release fractions indicate that the diffusivities in $\mathrm{SiC}$ need to be reduced by at least between 10 and $10^{2}$ at 1600 and $1700^{\circ} \mathrm{C}$, and between $10^{2}$ and $10^{3}$ at $1800^{\circ} \mathrm{C}$. As with silver and cesium, because of the lack of statistical significance of the PIE data at $1700^{\circ} \mathrm{C}$, the correction factor at $1700^{\circ} \mathrm{C}$ should be considered with care. 


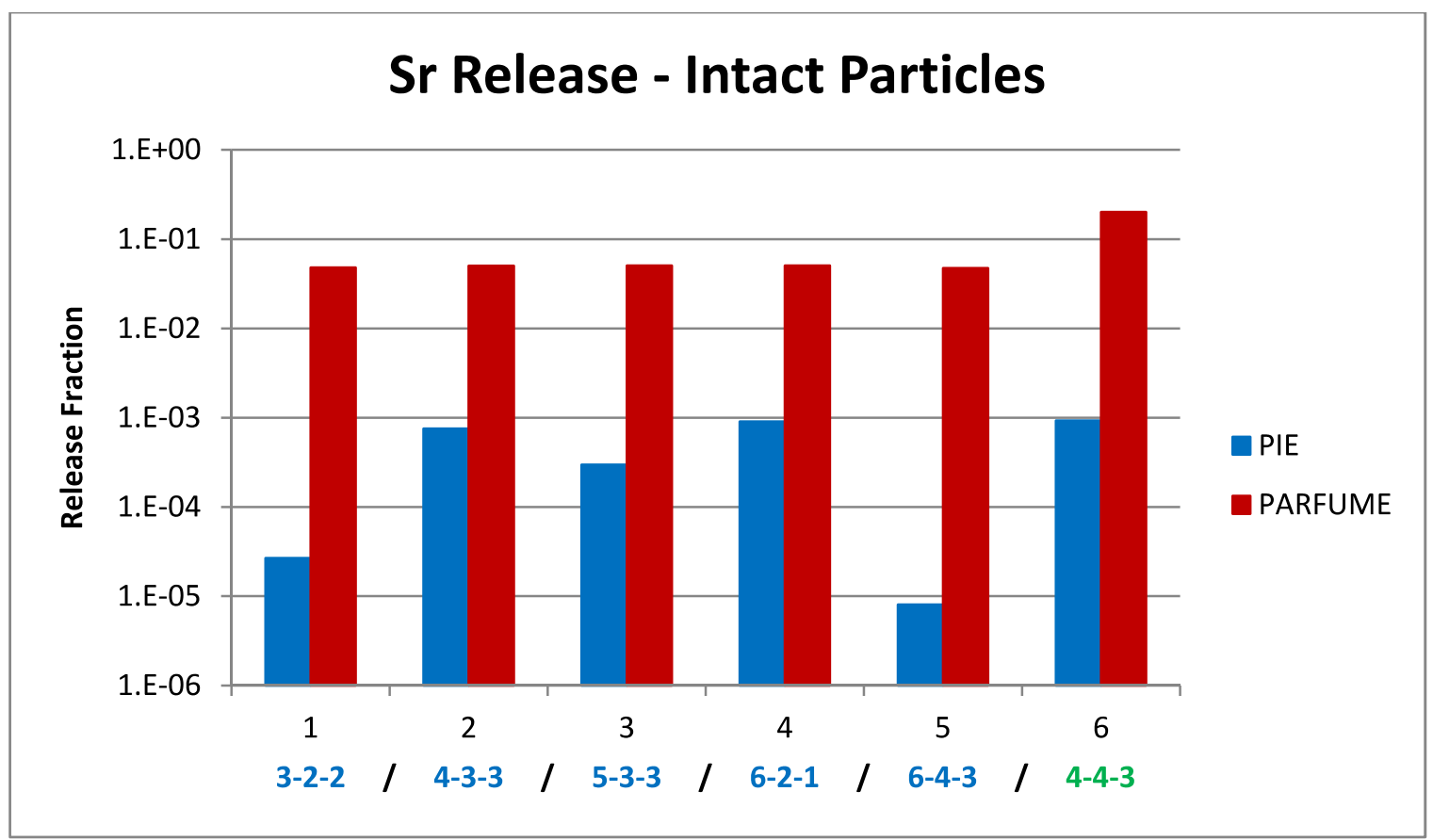

Figure 20. Strontium fractional release from compacts containing only intact particles.

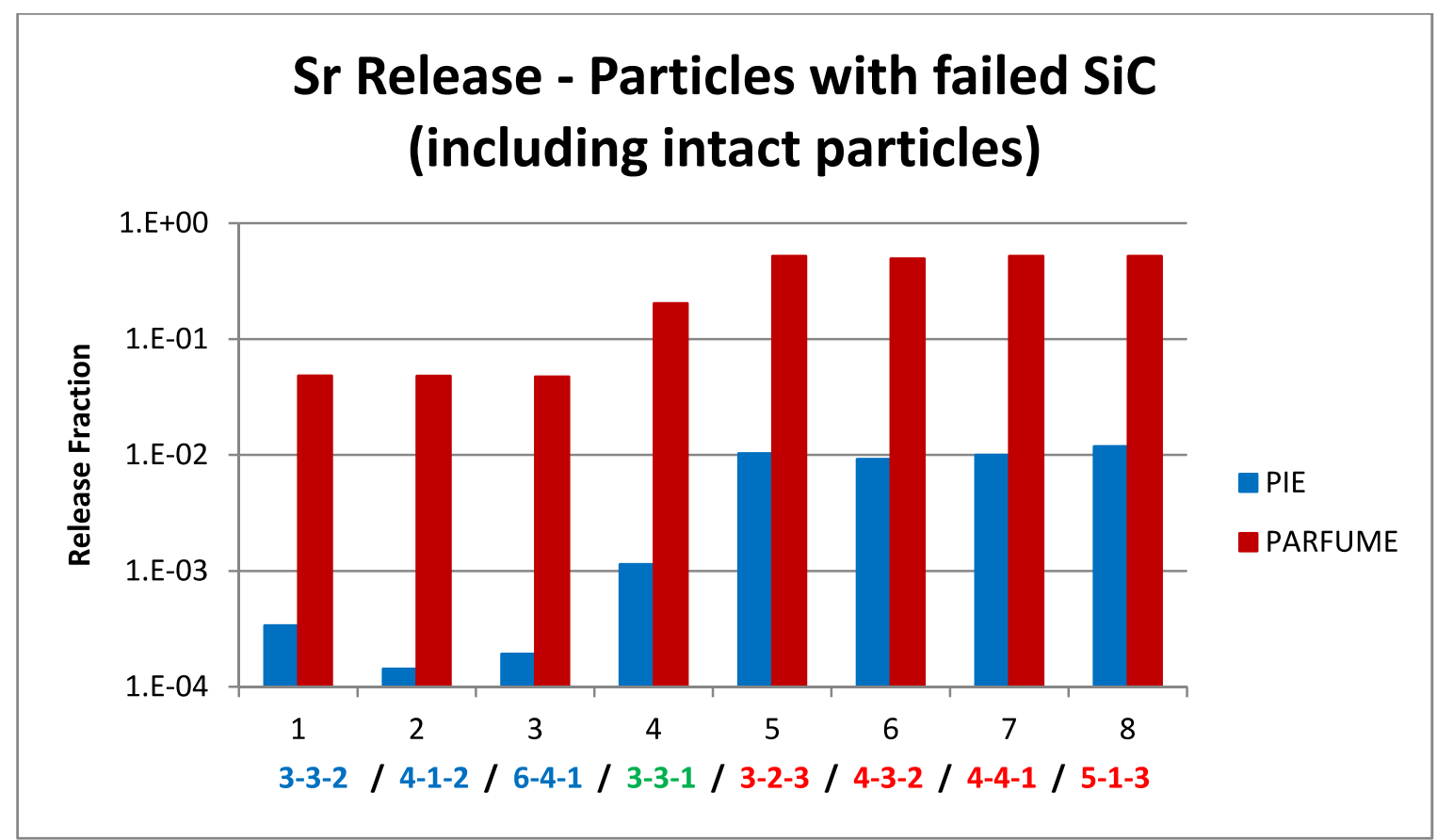

Figure 21. Strontium fractional release from compacts containing particles with failed SiC layers. PARFUME predictions include the release from intact particles. 


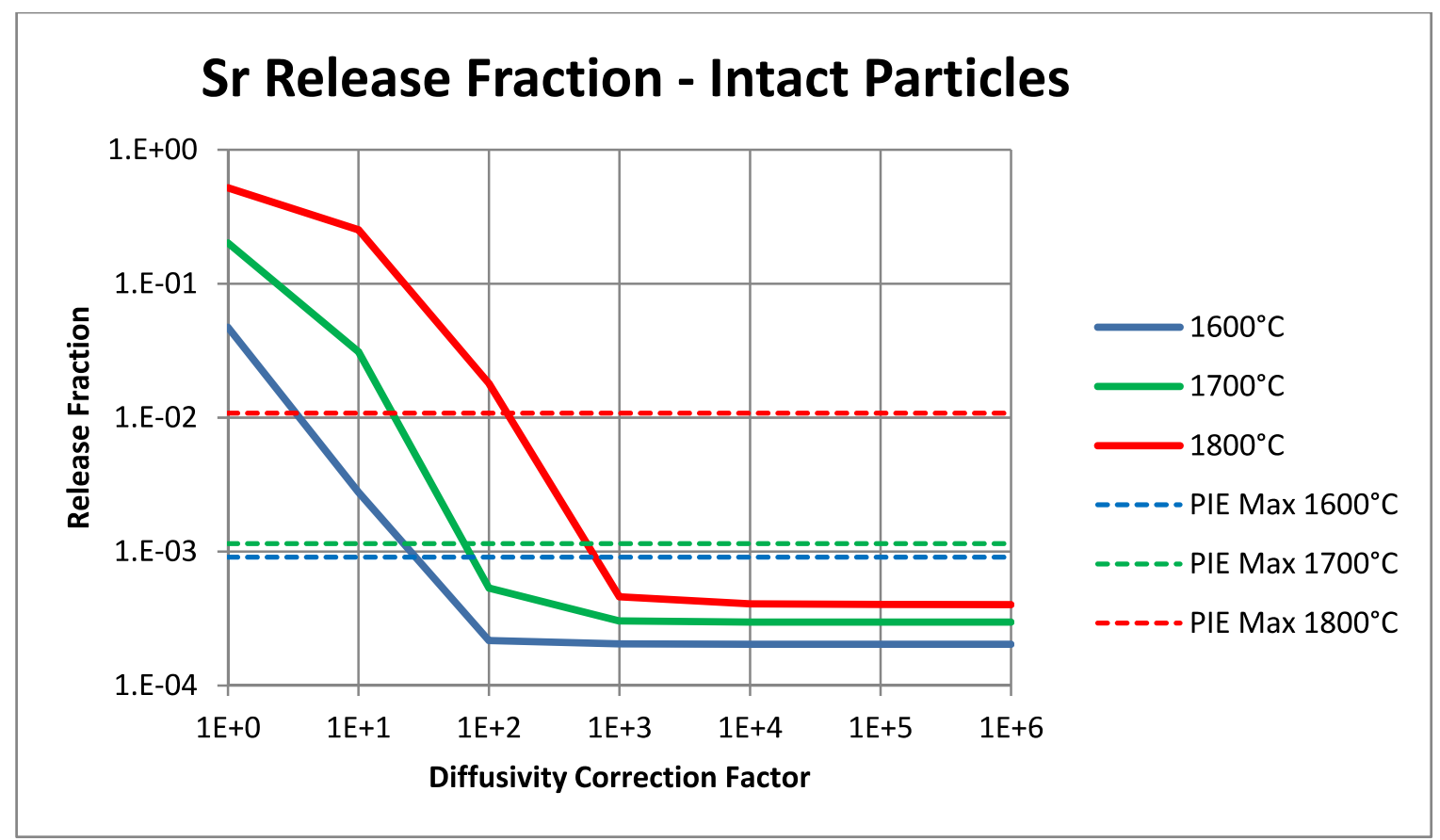

Figure 22. Calculated strontium release fraction versus diffusivity in SiC during safety testing.

\subsection{Krypton Release}

Krypton is unique because it has both the $\mathrm{SiC}$ and PyC layers as diffusion barriers. Therefore, Krypton release is indicative of the failure of all three coating layers, and is the primary indicator for total particle coating failure during a heating test.

For krypton, there is no reliable release data for compacts heated up at $1600^{\circ} \mathrm{C}$, partly due to the potential for background contamination from the hot cell contributing to the measured krypton activity, and partly because the release fractions were sufficiently low that released activity was below detection limits. The measured release, including background contamination, was $\leq 10^{-5}$ for all $1600^{\circ} \mathrm{C}$ tests, which indicates a low release from intact particles.

Compacts tested at 1700 and $1800^{\circ} \mathrm{C}$ all contained particles with failed SiC. Figure 23 shows the fractional release of krypton for these compacts. In Figure 23, Compact 4-3-2 is modeled with three particles with both failed IPyC and SiC layers and two particles with exposed kernels (see Section 4). For compacts containing particles with failed SiC, Figure 23 shows an overprediction by 1 order of magnitude at $1700^{\circ} \mathrm{C}$, and by up to 1.5 orders of magnitude at $1800^{\circ} \mathrm{C}$.

To be consistent with PIE observations, the particles with failed SiC layers are also modeled with failed IPyC layers, but intact OPyC layers. Therefore, the overprediction of the krypton release from compacts containing particles with failed $\mathrm{SiC}$ is attributed to the overestimation of the diffusivity of krypton in the kernel or in the $\mathrm{OPyC}$, or a combination of both. Historically, the diffusion of noble gases in PyC, including krypton, has been a major focus of study in bistructural isotropic-coated particles, and the diffusivity of krypton in PyC is better known than its diffusivity in the kernel. On the other hand, the best comparison arises from Compact 4-3-2, which is modeled with two exposed kernels and three particles with failed $\mathrm{SiC}$ (and consequently failed IPyC). This would indicate that the discrepancies between PARFUME and PIE are larger when modeling the release from particles with intact OPyC.

In the case of krypton, the paucity of safety testing data and the complexity of its release due to multiple retention barriers do not allow the determination of correction factors for the diffusivities in the kernel and the successive coating layers. 


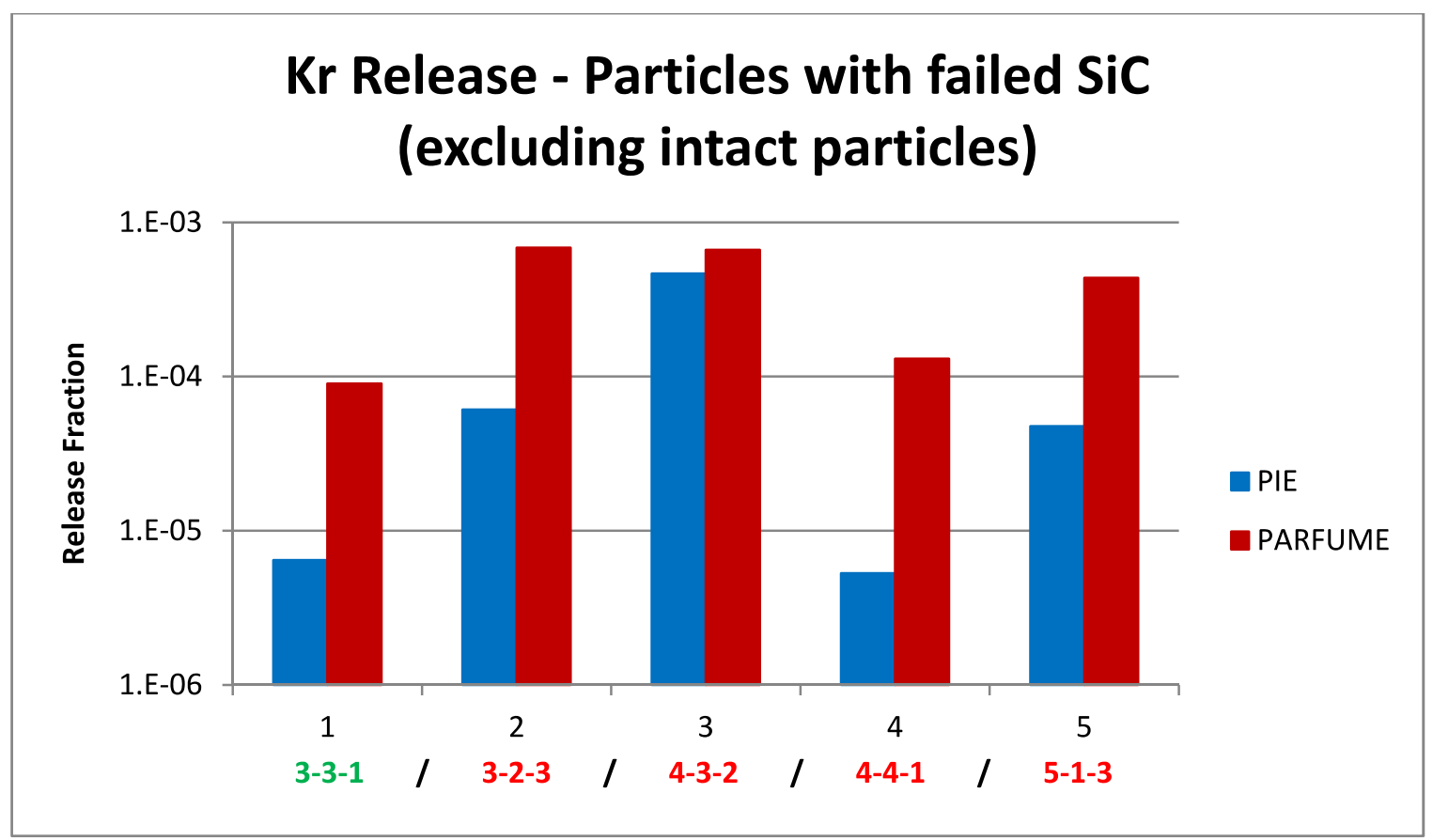

Figure 23. Krypton fractional release from compacts containing particles with failed SiC layers. PARFUME predictions exclude the release from intact particles. 


\section{CONCLUSION}

The PARFUME modeling code was used to predict fission product release from 14 TRISO-coated fuel compacts during AGR-1 safety tests at 1600,1700 , and $1800^{\circ} \mathrm{C}$. Predictions were then compared to PIE measurements.

Comparisons were made for both compacts containing only intact particles and for compacts containing particles with both failed IPyC and SiC layers. The latter comparisons theoretically allow for corrections to be made for the overestimation of the diffusivities of the fission products in the kernel, provided that the OPyC layer is non-retentive. In the case of significant release from intact particles, the former comparisons allow the determination of the overestimation of the diffusivity of fission products in the $\mathrm{SiC}$ layer.

The predictions showed different trends in the comparison to PIE measurements depending on the fission product species, which leads to different conclusions regarding the diffusivities used in the modeling of fission product transport:

- Silver

- The diffusivity of silver in $\mathrm{SiC}$ might be overestimated by a factor of at least $10^{2}$ to $10^{3}$ at $1600^{\circ} \mathrm{C}$ and $1700^{\circ} \mathrm{C}$, and at least 10 to $10^{2}$ at $1800^{\circ} \mathrm{C}$.

- The diffusivity of silver in UCO might also be overestimated, but the available data does not allow definite conclusions.

- Cesium

- The diffusivity of cesium in UCO might be overestimated by a factor of at least $10^{2}$ to $10^{3}$ at $1600^{\circ} \mathrm{C}, 10^{5}$ at $1700^{\circ} \mathrm{C}$, and $10^{3}$ at $1800^{\circ} \mathrm{C}$. The analysis of these overestimates takes into account corrections for the diffusivities of cesium in the kernel and in $\mathrm{SiC}$ during irradiation, as it was shown that these diffusivities are overestimated by a factor of 100 and by $30 \%$, respectively.

- The diffusivity of cesium in SiC might also be overestimated by a factor of 10 at $1600^{\circ} \mathrm{C}$ and $10^{3}$ at $1700^{\circ} \mathrm{C}$, as estimated by the comparison between calculated and measured release fractions from intact particles. There is no available estimate at $1800^{\circ} \mathrm{C}$ since all the compacts heated up at $1800^{\circ} \mathrm{C}$ contain particles with failed $\mathrm{SiC}$ layers whose release largely dominates the release from intact particles.

- The measured release of cesium from intact particles during the safety tests is comparable to the release measured at the end of irradiation, suggesting little to no additional release of cesium during safety testing.

- Strontium

- The diffusivity of strontium in $\mathrm{SiC}$ might be overestimated by a factor of 10 to $10^{2}$ at 1600 and $1700^{\circ} \mathrm{C}$, and $10^{2}$ to $10^{3}$ at $1800^{\circ} \mathrm{C}$. These values might be somewhat overestimated because available post-irradiation data do not allow an assessment of the strontium retention during irradiation to be made, which affects the magnitude of the calculated release during safety testing. On the other hand, possible strontium retention in the matrix would lead to an underestimation of these correction factors.

- The diffusivity of strontium in UCO cannot be derived from these heating tests. At this point, it is assumed to be modeled correctly using the IAEA kernel diffusivity.

- The measured release of strontium from intact particles during the safety tests is comparable to the release measured at the end of irradiation, suggesting little to no additional release of strontium during safety testing. 
- Krypton

- There is no reliable release data for compacts heated up at $1600^{\circ} \mathrm{C}$, which includes all the compacts containing only intact particles.

- At 1700 and $1800^{\circ} \mathrm{C}$, comparisons show an overprediction of the release from compacts containing particles with failed $\mathrm{SiC}$ by 1 to 1.5 orders of magnitude.

- Data from these heating tests are not sufficient to determine which of the TRISO-coating's layers diffusivities are under or overestimated.

Table 5 summarizes the correction factors to be applied to the IAEA diffusivities for the PARFUME predictions to match measured release fractions from the AGR-1 PIE.

Table 5. Diffusivity correction factors.

\begin{tabular}{|l|l|l|l|l|l|l|}
\hline & \multicolumn{3}{|c|}{ Correction Factor Kernel } & \multicolumn{3}{l|}{ Correction Factor SiC } \\
\cline { 2 - 8 } & $\mathbf{1 6 0 0}^{\circ} \mathbf{C}$ & $\mathbf{1 7 0 0}^{\circ} \mathbf{C}^{(\mathbf{c})}$ & $\mathbf{1 8 0 0}^{\circ} \mathbf{C}$ & $\mathbf{1 6 0 0}^{\circ} \mathbf{C}$ & $\mathbf{1 7 0 0}^{\circ} \mathbf{C}^{(\mathbf{c})}$ & $\mathbf{1 8 0 0}^{\circ} \mathbf{C}$ \\
\hline Silver & - & - & - & $10^{2}-10^{3}$ & $10^{2}-10^{3}$ & $10-10^{2}$ \\
\hline Cesium $^{(\mathbf{a})}$ & $10^{2}-10^{3}$ & $10^{5}$ & $10^{3}$ & 10 & $10^{3}$ & - \\
\hline Strontium $^{(\mathbf{b})}$ & - & - & - & $10-10^{2}$ & $10-10^{2}$ & $10^{2}-10^{3}$ \\
\hline Krypton & - & - & - & - & - & - \\
\hline
\end{tabular}

a. Diffusivity during irradiation reduced by a factor of 100 in kernel, and by $30 \%$ in SiC.

b. Possible retention in the matrix would lead to an underestimation of the corrections factors.

c. Gross estimates of the correction factors at $1700^{\circ} \mathrm{C}$ because of the lack of statistical significance of the PIE data.

The estimated correction factors to the diffusivities enable a better match between the modeling predictions and the safety testing results. They are based on limited statistics and on safety testing data that show differences from one compact to another at a given temperature, which leads to uncertainties in the assessment of these correction factors. This is especially the case for the correction factors at $1700^{\circ} \mathrm{C}$ that are based on the use of one or two data points, which limits the statistical significance of the analysis. Furthermore, in the case of strontium, the uncertainty on strontium retention in the matrix translates into a large uncertainty on the correction factors on the diffusivity of strontium in SiC. At this point, all these correction factors are preliminary, while a more definitive assessment must await additional data from future AGR safety testing campaigns. 


\section{REFERENCES}

American Society of Mechanical Engineers, "NQA-1-2008; 1a-2009 Quality Assurance Requirements for Nuclear Facility Applications," March 2008 (Addenda August 2009).

C. A. Baldwin, J. D. Hunn, R. N. Morris, F. C. Montgomery, C. M. Silva, P. A. Demkowicz, 2014, "First elevated-temperature performance testing of coated particle fuel compacts from the AGR-1 irradiation experiment," Nuclear Engineering and Design, Vol. 271, pp. 131-141.

CEGA Corporation, "NP-MHTGR Material Models of Pyrocarbon and Pyrolytic Silicon Carbide," CEGA-002820, Rev. 1, July 1993.

B. P. Collin, “AGR-2 Irradiation Experiment Test Plan,” PLN-3798, Idaho National Laboratory, Rev. 1, October 2011.

B. P. Collin, “AGR-1 Irradiation Test Final As-Run Report,” INL/EXT-10-18097, Idaho National Laboratory, Rev. 2, August 2014a.

B. P. Collin, "Comparison of fission product release predictions using PARFUME with results from the AGR-1 irradiation experiment," INL/EXT-14-31975, Idaho National Laboratory, September 2014b.

P. A. Demkowicz, “AGR-1 Post-Irradiation Examination Plan,” PLN-2828, Idaho National Laboratory, Rev. 1, March 2010.

P. A. Demkowicz, "Inter-office Memorandum: AGR-1 Safety Test Plan,” CCN-227349, May 2012a.

P. A. Demkowicz, D. V. Laug, D. M. Scates, E. L. Reber, L. G. Roybal, J. B. Walter, J. M. Harp, R. N. Morris, 2012b, "The Fuel Accident Condition Simulator (FACS) furnace system for high temperature performance testing of VHTR fuel," Nuclear Engineering and Design, Vol. 251, pp. 164-172.

G. L. Hawkes, “AGR-1 Daily As-run Thermal Analyses,” ECAR-968, Idaho National Laboratory, Rev. 2, January 2012.

IAEA, "Fuel performance and fission product behaviour in gas cooled reactors," TECDOC-978, International Atomic Energy Agency, November 1997.

G. R. Longhurst, D. F. Holland, J. L. Jones, B. J. Merrill, “TMAP4 User's Manual,” EGG-FSP-10315, June 1992.

J. T. Maki, “AGR-1 Irradiation Experiment Test Plan,” INL/EXT-05-00593, Idaho National Laboratory, Rev. 3, October 2009.

G. K. Miller, D. L. Knudson, “AGR-1 Pre-Test Prediction Analysis using the PARFUME Code," EDF5741, Idaho National Laboratory, Rev. 1, April 2007.

G. K. Miller, D. A. Petti, J. T. Maki, D. L. Knudson, "PARFUME Theory and Model Basis Report," INL/EXT-08-14497, Idaho National Laboratory, September 2009.

R. N. Morris, P. A. Demkowicz, J. D. Hunn, C. A. Baldwin, E. L. Reber, "Performance of AGR-1 high temperature reactor fuel during post-irradiation heating tests," HTR2014-31135, Proceedings of the HTR2014 Conference, Weihai, China, October 27-31, 2014.

J. Simonds, “Technical Program Plan for the Very High Temperature Reactor Technology Development Office/Advanced Gas Reactor Fuel Development and Qualification Program," PLN-3636, Idaho National Laboratory, Rev. 3, May 2014.

J. W. Sterbentz, "JMOCUP As-Run Daily Depletion Calculation for the AGR-1 Experiment in ATR B-10 position," ECAR-958, Idaho National Laboratory, Rev. 1, August 2011.

J. W. Sterbentz, "JMOCUP As-Run Daily Depletion Calculation for the AGR-1 Experiment in ATR B-10 position,” ECAR-958, Idaho National Laboratory, Rev. 2, September 2013. 


\section{APPENDIX A}

\section{Considerations on Release Fractions}

This appendix presents theoretical considerations on the calculation of the release fraction after safety testing by PIE and PARFUME.

The theoretical development considers the release from a particle, but the generalization to the release from a compact is straightforward. The release fraction " $\mathrm{f}$ " of a fission product from a TRISO particle is given by the relation:

$$
\mathrm{f}=\frac{\mathrm{R}}{\mathrm{S}}
$$

where " $\mathrm{R}$ " is the amount of fission product released and " $\mathrm{S}$ " is the fission product source.

In the case of irradiation, Equation (1) can be re-written as:

$$
\mathrm{R}_{\text {irr }}=\mathrm{f}_{\text {irr }} * \mathrm{~S}_{\mathrm{irr}}
$$

where " $\mathrm{S}_{\text {irr }}$ " represents the total inventory of the fission product under consideration that is produced during irradiation, and " $\mathrm{R}_{\text {irr }}$ " is the amount of the fission product that is released during irradiation. At the end of irradiation, the particle is left with the inventory:

$$
\mathrm{S}_{\mathrm{irr}}-\mathrm{R}_{\mathrm{irr}}=\left(1-\mathrm{f}_{\mathrm{irr}}\right) * \mathrm{~S}_{\mathrm{irr}}
$$

since the fraction " $\mathrm{f}_{\text {irr" }}$ " of the source " $\mathrm{S}_{\text {irr }}$ " has been released.

In the case of a safety testing, Equation (1) can be re-written as:

$$
\mathrm{R}_{\mathrm{st}}=\mathrm{f}_{\mathrm{st}} * \mathrm{~S}_{\mathrm{st}}
$$

where " $\mathrm{S}_{\mathrm{st}}$ " represents the inventory inside the particle before the safety test which is readily available for release during the safety test, and " $\mathrm{R}_{\mathrm{st}}$ " is the amount of fission product that is released during the safety test. Equation (4) gives the intrinsic release fraction " $\mathrm{f}_{\mathrm{st}}$ " of the safety test by dividing the release during the safety test by the inventory available for release.

In PARFUME and PIE, the release fraction is calculated by normalizing the release from the safety test $\left(\mathrm{R}_{\mathrm{st}}\right)$ by the total inventory of the fission product produced during irradiation $\left(\mathrm{S}_{\mathrm{irr}}\right)$. The subsequent release fraction " $\mathrm{f}_{\mathrm{p}}$ " is therefore given by:

$$
\mathrm{f}_{\mathrm{p}}=\frac{\mathrm{R}_{\mathrm{st}}}{\mathrm{S}_{\mathrm{irr}}}
$$

By noticing from Equations (3) and (4) that $S_{s t}=\left(1-f_{\text {irr }}\right) * S_{\text {irr }}$, Equation (5) becomes:

$$
\mathrm{f}_{\mathrm{p}}=\frac{\mathrm{f}_{\mathrm{st}} * \mathrm{~S}_{\mathrm{st}}}{\mathrm{s}_{\mathrm{st}} /\left(1-\mathrm{f}_{\mathrm{irr}}\right)}=\left(1-\mathrm{f}_{\mathrm{irr}}\right) * \mathrm{f}_{\mathrm{st}}
$$

Therefore, PARFUME and PIE do not calculate the true intrinsic release fraction from the safety test $\left(f_{s t}\right)$, but rather a release fraction $\left(f_{p}\right)$ that depends on the release during irradiation $\left(f_{\text {irr }}\right)$.

The reason for this approximation is that PIE does not have access to the inventory at the end of irradiation $\left(\mathrm{S}_{\mathrm{st}}\right)$ since it would require to deconsolidate the compact. In most cases $(\mathrm{Cs}, \mathrm{Sr}, \mathrm{Kr})$ the release during irradiation is small enough so " $\mathrm{f}_{\mathrm{p}}$ " and " $\mathrm{f}_{\mathrm{st}}$ " are similar, but in the case of silver the release during irradiation can reach values in excess of $50 \%$, making " $\mathrm{f}_{\mathrm{p}}$ " less accurate to predict the fractional release during safety testing. Furthermore, the discrepancy in calculated (PARFUME) and measured (PIE) silver release during irradiation (Collin 2014b) makes it harder to compare silver release after safety testing because the "error" due to the factor " $1-f_{\text {irr" }}$ " is different for PARFUME and PIE. 